\title{
$d b / d b$ Mice Exhibit Features of Human Type 2 Diabetes That Are Not Present in Weight-Matched C57BL/6J Mice Fed a Western Diet
}

\author{
Susan J. Burke, ${ }^{1}$ Heidi M. Batdorf, ${ }^{2,3}$ David H. Burk, ${ }^{4}$ Robert C. Noland, ${ }^{3}$ Adrianna E. Eder, ${ }^{5}$ \\ Matthew S. Boulos, ${ }^{5}$ Michael D. Karlstad, ${ }^{5}$ and J. Jason Collier ${ }^{2}$ \\ ${ }^{1}$ Laboratory of Immunogenetics, Pennington Biomedical Research Center, Baton Rouge, LA 70808, USA \\ ${ }^{2}$ Laboratory of Islet Biology and Inflammation, Pennington Biomedical Research Center, Baton Rouge, LA 70808, USA \\ ${ }^{3}$ Skeletal Muscle Metabolism Laboratory, Pennington Biomedical Research Center, Baton Rouge, LA 70808, USA \\ ${ }^{4}$ Cell Biology and Bioimaging Core Facility, Pennington Biomedical Research Center, Baton Rouge, LA 70808, USA \\ ${ }^{5}$ Department of Surgery, Graduate School of Medicine, University of Tennessee Health Science Center, Knoxville, TN 37920, USA
}

Correspondence should be addressed to J. Jason Collier; Jason.collier@pbrc.edu

Received 12 May 2017; Revised 24 July 2017; Accepted 25 July 2017; Published 6 September 2017

Academic Editor: Hiroshi Okamoto

Copyright (C) 2017 Susan J. Burke et al. This is an open access article distributed under the Creative Commons Attribution License, which permits unrestricted use, distribution, and reproduction in any medium, provided the original work is properly cited.

To understand features of human obesity and type 2 diabetes mellitus (T2D) that can be recapitulated in the mouse, we compared C57BL/6J mice fed a Western-style diet (WD) to weight-matched genetically obese leptin receptor-deficient mice ( $d b / d b)$. All mice were monitored for changes in body composition, glycemia, and total body mass. To objectively compare diet-induced and genetic models of obesity, tissue analyses were conducted using mice with similar body mass. We found that adipose tissue inflammation was present in both models of obesity. In addition, distinct alterations in metabolic flexibility were evident between WD-fed mice and $d b / d b$ mice. Circulating insulin levels are elevated in each model of obesity, while glucagon was increased only in the $d b / d b$ mice. Although both WD-fed and $d b / d b$ mice exhibited adaptive increases in islet size, the $d b / d b$ mice also displayed augmented islet expression of the dedifferentiation marker Aldh1a3 and reduced nuclear presence of the transcription factor Nkx6.1. Based on the collective results put forth herein, we conclude that $d b / d b$ mice capture key features of human T2D that do not occur in WD-fed C57BL/6J mice of comparable body mass.

\section{Introduction}

Obesity is a major risk factor for insulin resistance, metabolic syndrome, and type 2 diabetes (T2D) [1,2]. In the human population, body mass index calculations are often used to determine metabolic disease risk [3], with stratifications ranging from nonobese $\left(18.5-24.9 \mathrm{~kg} / \mathrm{m}^{2}\right)$ to overweight $\left(25-30 \mathrm{~kg} / \mathrm{m}^{2}\right)$ to obese $\left(>30 \mathrm{~kg} / \mathrm{m}^{2}\right)$. Different metabolic disturbances and degrees of risk are often detected within each subgroup $[3,4]$. Consequently, increasing body mass in the form of excess adiposity is often detrimental to whole body glucose homeostasis due to a chronic low-grade inflammatory condition [5].

On a cellular level, adipocytes play a key role in both fat storage and production of soluble factors that regulate insulin sensitivity [6]. In addition, whether excess intracellular lipid content is stored in adipose tissue or in lean tissues has major implications for disease risk [7, 8]. Storage of lipid in lean tissues is detrimental and produces adverse metabolic outcomes [7]. The chronic low-grade inflammation associated with an overabundance of adipose tissue often leads to endocrine alterations and dysfunction of other tissues, such as the skeletal muscle and liver [5].

During insulin resistance and "prediabetes", islet $\beta$-cells typically increase in number via proliferation of the existing cellular population [9-11]. In addition, insulin output is enhanced prior to diabetes onset to compensate for reduced action of the hormone in peripheral tissues (e.g., skeletal muscle and liver). Once a decrease in islet $\beta$-cell insulin secretion and diminutions in the $\beta$-cell population or both 
occur, clinical onset of T2D ensues [12]. Clearly, there are stages of disease progression with earlier metabolic aberrations (e.g., hyperinsulinemia) that ultimately indicate risk of onset of T2D. Hyperinsulinemia and insulin resistance may often go undiagnosed but are important "prediabetic" indicators of future disease risk. Progression to overt diabetes requires a diminution in pancreatic islet $\beta$-cell mass, $\beta$-cell function, or both $[1,9,13]$.

Pancreatic islet $\beta$-cells from human subjects with T2D display markers of dedifferentiation. For example, increased abundance of Aldh1a3 and reduced nuclear presence of the transcription factor Nkx6.1 were observed in pancreatic islets from T2D, but not in healthy controls [14]. Nkx6.1 is important for islet $\beta$-cell development, suppressing expression of the glucagon gene, and for maintenance of adult $\beta$-cell phenotype $[15,16]$. With elevated glucagon levels being a long known feature of uncontrolled diabetes [17], it is not surprising that losses in key transcription factors within islet $\beta$-cells could lead to dysregulation of overall islet hormone production.

During a comparison of C57BL/6J mice fed a high-fat, sucrose-enriched Western diet (WD) with weight-matched genetically obese leptin receptor-deficient mice $(d b / d b)$, several key findings arose: (1) WD-fed and $d b / d b$ mice accumulate body weight and fat mass over time at rates higher than their respective lean control counterparts but similar to each other. (2) Both WD-fed C57BL/6J mice and $d b / d b$ mice are hyperinsulinemic, but only $d b / d b$ mice are hyperglycemic. (3) Circulating insulin levels are elevated in both models of obesity, but glucagon is increased only in the $d b / d b$ mice. (4) While both WD-fed C57BL/6J mice and $d b / d b$ mice exhibit adaptive increases in islet size, the $d b / d b$ mice also display increased islet expression of the dedifferentiation marker Aldh1a3. (5) There is reduced nuclear presence of the transcription factor Nkx6.1 in $d b / d b$ mice when compared with mice fed the WD. We conclude that $d b / d b$ mice capture key features of human T2D that do not occur in weight-matched WD-fed C57BL/6J mice.

\section{Methods}

2.1. Animals and Reagents. Nine-week-old male C57BL/6J (stock number 00664) and 5-week-old male $d b /+$ and $d b / d b$ mice (B6.BKS(D)-Lepr ${ }^{d b} / \mathrm{J}$; stock number 00697) were acquired from the Jackson Laboratories (Bar Harbor, Maine). These mice were allowed to acclimate to the photoperiod (12-hour light/12-hour dark) and temperature conditions $\left(22 \pm 1^{\circ} \mathrm{C}\right)$ for one week prior to the start of the study. C57BL/6J mice were randomized into their respective dietary group assignments based on body weight and blood glucose measurements such that no significant differences existed between groups at baseline. At 10 weeks of age, 3 separate cohorts of mice were started on either control diet (Cat number 98052602; Research Diets Inc., New Brunswick, NJ) or Western diet (Cat number D12079B; Research Diets Inc.) for 4,12 , and 20 weeks. The $d b / d b$ and $d b /+$ mice were each given access to Lab Diet 5001 ad libitum throughout the study to represent conditions similar to those used for colony maintenance at the Jackson laboratory. Blood glucose was measured weekly using an Accu-Chek Aviva Plus Glucometer (Roche Diagnostic, Indianapolis, IN). Weekly measurements of body mass and composition (fat, lean, and fluid mass) were assessed by NMR using a Bruker Minispec LF50 Time-Domain NMR system. Upon completion of the study feeding period, animals were sacrificed by $\mathrm{CO}_{2}$ asphyxiation and decapitation. Whole pancreata were fixed in $10 \%$ neutral-buffered formalin overnight prior to sectioning and embedding. Fat depots, liver, and skeletal muscle were flash frozen in liquid nitrogen and stored at $-80^{\circ} \mathrm{C}$. Serum was collected from trunk blood or cardiac sticks. Pancreatic islets were isolated as described previously [18]. Relevant animal procedures were approved by the PBRC and the University of Tennessee Institutional Animal Care and Use Committees.

\subsection{Insulin Tolerance Test, Islet Histology, and Substrate} Oxidation. Mice were fasted for $2 \mathrm{~h}$ and were injected intraperitoneally with 0.75 units/kg Humulin R insulin as previously described [19]. Islet histology procedures have been described $[19,20]$. Briefly, the antibodies used were as follows: insulin (Invitrogen; 18-0067; used at 1:800), glucagon (Cell Signaling Technologies; 8233; used at 1:400), Aldh1a3 (Novus Biologicals; NBP2-15339; used at 1:100), and Nkx6.1 (F55A12; $1: 200 ;[21])$. All antibodies were incubated overnight at $4^{\circ} \mathrm{C}$ and detected with either Alexa Fluor secondary conjugation (Alexa 488, 594), except for Nkx6.1, which was detected using a biotin/streptavidin exposure method. Substrate oxidation was measured in the liver, and gastrocnemius muscle homogenates were prepared and used as described previously [22, 23]. Briefly, using $\left[1-{ }^{14} \mathrm{C}\right]$ palmitate $(100 \mu \mathrm{M})$, both complete $\left({ }^{14} \mathrm{CO}_{2}\right)$ and incomplete $\left({ }^{14} \mathrm{C}\right.$-acid soluble metabolites (ASMs)) fatty acid oxidation were assessed \pm varying doses of unlabeled pyruvate $(0,0.1,1$, and $10 \mathrm{mM})$ to assess metabolic flexibility.

2.3. Total RNA Extraction, cDNA Synthesis, and Real-Time RT-PCR. All procedures have been described previously $[24,25]$. Briefly, total RNA was extracted from mouse islets, liver, and epididymal fat depots using an RNeasy Mini Kit (Qiagen). RNA quality and quantity was assessed using a Nanodrop spectrophotometer (Thermo Scientific). cDNA was generated from total RNA using the iScript cDNA synthesis kit (Bio-Rad). Relative mRNA abundance was measured by real-time PCR using the iTaq Universal SYBR Green Supermix (Bio-Rad) on a CFX96 instrument (Bio-Rad). Transcript levels were normalized with the housekeeping gene Ppia or Rs9. Primer pairs were designed using the Primer3Plus software.

2.4. Serum ELISA. The following kits were used to measure serum factors: Mouse/Rat Leptin Quantikine ELISA kit (Cat number MOB00) from R\&D Systems (Minneapolis, $\mathrm{MN}$ ), Mouse Insulin ELISA kit (Cat number 10-1247-01) and Glucagon ELISA kit (Cat number 10-1271-01) from Mercodia (Uppsala, Sweden), Corticosterone ELISA kit (Cat number ADI-900-097) from Enzo Life Sciences (Farmingdale, NY), and the Mouse Adiponectin ELISA kit (Cat number 80569) from Crystal Chem (Downers Grove, 
IL). Manufacturer's recommended protocols were used for all serum measurements.

2.5. Tissue Acyl Glycerol Measurements. Isolated liver (30 mg) tissue was homogenized in 5\% NP-40 solution $(300 \mu \mathrm{L})$ and heated twice to $95^{\circ} \mathrm{C}$ to solubilize all acyl glycerol species. Samples were centrifuged at maximum speed for 2 minutes, and supernatant was removed to a clean tube to prevent contamination with insoluble material. The transferred samples were diluted 10 -fold in water before proceeding with the detection portion of the assay. Acyl glycerol content was measured using the Triglyceride Determination kit (Cat number TR0100) from Sigma Aldrich according to the manufacturer's directions.

2.6. Statistics. The data were evaluated with the GraphPad Prism 6.0 statistical analysis software. Data were analyzed by either one-way ANOVA using a Tukey post hoc, repeated measures ANOVA (for longitudinal measures of blood glucose, body weight, and body composition), two-way repeated measures ANOVA with Bonferroni post hoc test for multiple comparisons (substrate oxidation), or two-tailed Student's $t$-test. Individual $p$ values are given in the figure legends.

\section{Results}

3.1. C57BL/6J Mice Fed a High-Fat, Sucrose-Enriched Diet Gain Weight but Do Not Develop Hyperglycemia. Over the course of 20 weeks, male C57BL/6J mice were fed either a high-fat, high-sucrose Western diet (WD) or sucrosematched low-fat control diet (CD). Blood glucose remained stable in both groups of mice during this 20-week period (Figure 1(a)). The study conditions were closely monitored so that mice fed the WD could be weight matched with $d b /$ $d b$ mice. The $d b / d b$ mice on the C57BL/6 genetic background, which develop obesity secondary to leptin resistance, display noticeable elevations in blood glucose early in their lifespan (Figure 1(b)). The $d b / d b$ mice were compared to lean littermate heterozygous controls for the leptin receptor mutation $(d b /+)$. The hyperglycemia in $d b / d b$ mice was maintained throughout the eight-week study period. C57BL/6J mice fed the WD gained $22.7 \mathrm{~g}$ of total body mass versus $13.8 \mathrm{~g}$ for mice fed the CD (Figures $1(\mathrm{c})$ and $1(\mathrm{e})$ ). The $d b / d b$ mice were fed ad libitum with a low-fat diet $(6 \% \mathrm{kcal})$ to mimic conditions commonly used for this strain. On the low-fat diet, the $d b /+$ animals gained $7.1 \mathrm{~g}$, while $d b / d b$ mice increased total body weight by $24 \mathrm{~g}$ (Figures 1(d) and 1(f)). Therefore, although similar accumulation of body mass was observed in C57BL/6J on a Westernstyle diet when compared to $d b / d b$ mice on a low-fat diet, there was a noticeable difference in glycemic control between these mouse models of obesity.

3.2. db/db Mice Accumulate Adipose Tissue on a Low-Fat Diet Similar to That Seen with C57BL/6J Mice Fed a Western Diet. Because the accrual of adipose tissue (fat mass) impacts systemic metabolic parameters [6], we investigated the accumulation of this tissue depot in both diet-induced and genetic models of obesity. C57BL/6J mice fed the WD displayed consistently elevated fat mass over mice in the $\mathrm{CD}$ group
(Figure 2(a)). We found that $d b / d b$ mice between the ages of 6 and 14 weeks of age gained a similar amount of fat mass ( $14.5 \mathrm{~g})$ as the C57BL/6J mice on a WD for 20 weeks (13.25 g; compare Figure 2(c) with Figure 2(d)). However, $d b /+$ mice did not accumulate significant amount of fat mass between the ages of 6 and 14 weeks $(0.56 \mathrm{~g}$; Figures 2(b) and 2(d)), which we suspect is due to the low amount of fat and sucrose in this diet. When viewed from a perspective of fat mass as a percentage of total body mass, the C57BL/6J mice start out with a relatively low total body fat percentage $(\sim 6 \%)$ but go over $30 \%$ body fat by week 20 of WD feeding (Figure 2(e)). Alternatively, the $d b / d b$ mice start out near $30 \%$ total body fat at 6 weeks of age and increased to over $40 \%$ at 14 weeks of age (Figure 2(f)). When lean mass was examined, both C57BL/6J mice fed a WD and $d b / d b$ mice display similar increases in total lean mass, although the $d b / d b$ mice had a lower total percentage of whole body lean mass (Figure 3). Similar findings were observed when measuring fluid mass (Figure 3).

3.3. Elevations in Serum Leptin Are Consistent with Increases in Body Weight and Adiposity in Both Models of Obesity, While Elevated Corticosterone Is Specific to $\mathrm{db} / \mathrm{db}$ Mice. Leptin is a fat cell-derived hormone that has important roles in regulating satiety. Serum leptin clearly increases with body weight in WD-fed mice and is also elevated as the mice get older (Figure 4(a)). In addition, $d b / d b$ mice have elevations in serum leptin over their lean counterparts (Figure 4(b)). By contrast, corticosterone is relatively stable in the serum of WD-fed mice (Figure 4(c)) but elevated in $d b / d b$ mice (Figure 4(d)). Adiponectin, also derived from adipose tissue, was not impacted by body weight, adiposity, or age of the mice (Figures 4(e) and 4(f)).

\subsection{There Is Clear Evidence of Inflammation in Adipose} Tissue from C57BL/6J Mice Fed a WD and in db/db Mice. With clear increases in fat mass accumulation between WD and $d b / d b$ mice (Figure 2(c) versus Figure 2(d)), we next measured the expression of genes involved in inflammatory responses using isolated epididymal white adipose tissue (eWAT). Expression of the Ill $\alpha$ gene, which encodes a proinflammatory cytokine, was strongly upregulated in animals fed WD for 12 weeks relative to mice eating the $\mathrm{CD}$ (Figure 5(a)). By 20 weeks, mice on the control diet were also displaying elevations in this cytokine (Figure 5(a)); in our view, this increase in inflammation in control mice is most likely due to aging. Notably, expression of IL- $1 \alpha$ was not significantly higher in eWAT from $d b / d b$ mice relative to $d b /+$ mice (Figure 5(b)). Nucleotide-binding oligomerization (NOD) domain-like receptors (NLRs) are in the family of pattern recognition receptors and have been shown to regulate adipocyte differentiation in vitro [26]. We observed that expression of NOD1 is suppressed in mice fed the WD (Figure 5(c)) and in $d b / d b$ mice relative to lean controls (Figure 5(d)). Ccl2, a chemokine that recruits monocytes and macrophages, was more highly expressed in both WDfed mice (Figure 5(e)) and in $d b / d b$ mice (Figure 5(f)), relative to their respective lean controls. Moreover, transcript levels of $C d 68$, a macrophage marker, were elevated at 12 

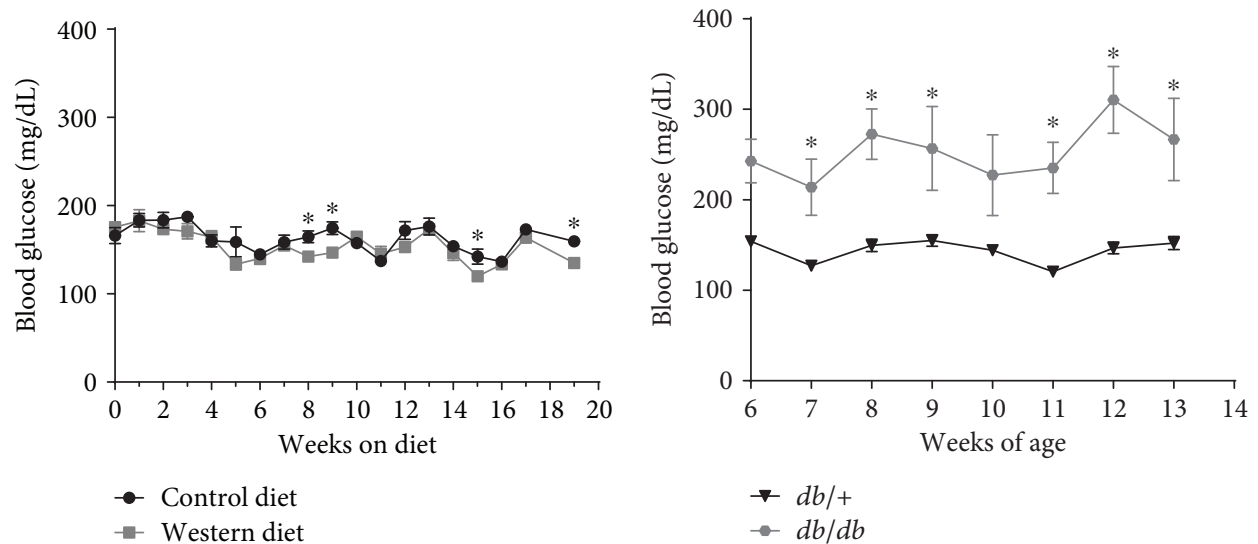

(a)

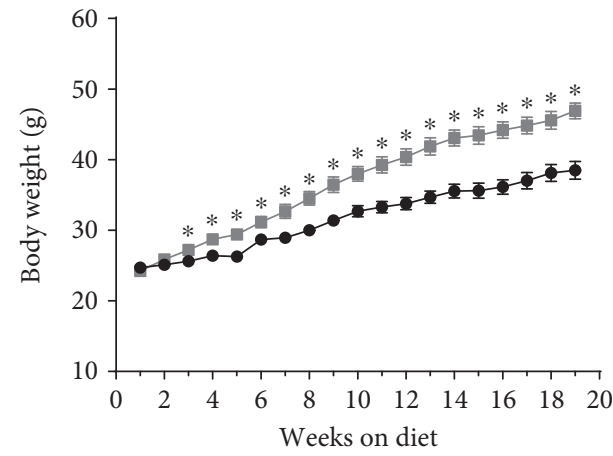

(b)

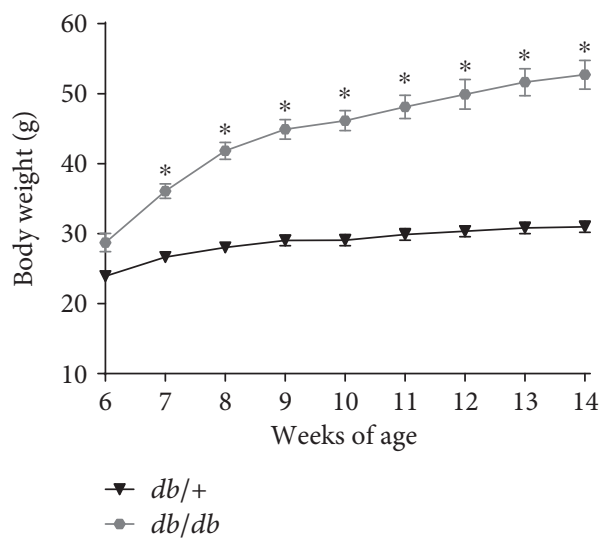

(c)

(d)

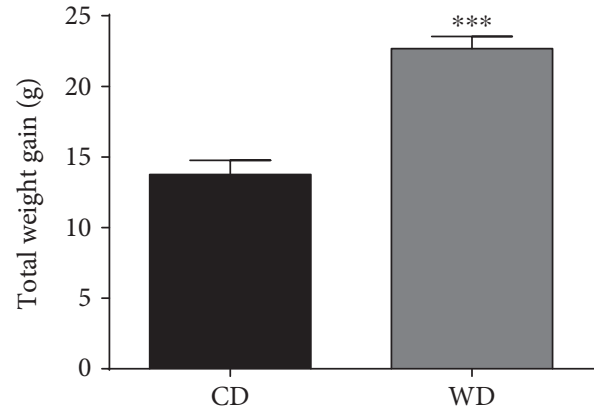

(e)

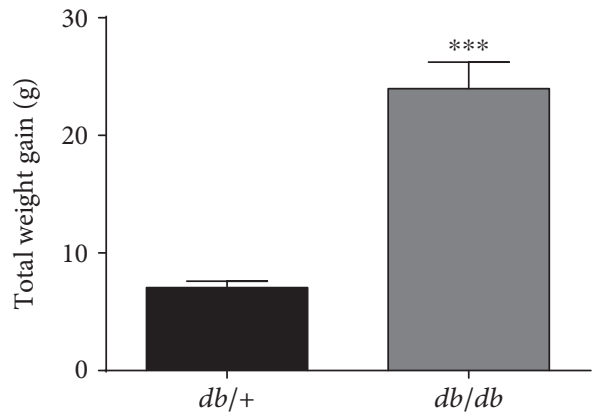

(f)

FIGURE 1: Hyperglycemia develops in genetically driven, but not diet-induced obesity. Blood glucose (a) and body weight (c) in male C57BL/ $6 \mathrm{~J}$ mice fed either control or Western diet for 20 weeks. Total weight gain (e) at the end of the 20 -week feeding period. Blood glucose (b) and body weight (d) in male $d b /+$ and $d b / d b$ mice between 6 and 14 weeks of age. Total weight gain by 14 weeks of age (f). For body weight measurements ( $c$ and d), $y$-axes are set to the same scale for comparison between study groups. $n=8$ per group; means \pm SEM; ${ }^{* * *} p<0.001$ versus control; ${ }^{*} p<0.05$ versus control by repeated measures ANOVA. CD: control diet; WD: Western diet.

weeks by WD feeding (Figure $5(\mathrm{~g}))$ and also enhanced in eWAT from $d b / d b$ mice (Figure $5(\mathrm{~h}))$.

3.5. There Is Elevated Expression of Glucose 6-Phosphatase, Acetyl Co-A Carboxylase, and Increased Acyl Glycerols in the Liver of $d b / d b$ Mice. Because severe insulin resistance in the liver is sufficient to create whole body glucose intolerance and elevations in blood glucose [27], we compared the expression of metabolic enzyme genes expressed in the livers of $d b / d b$ mice and mice fed a WD. Livers from $d b / d b$ mice displayed much higher expression of the gene encoding glucose 6-phosphatase (Figure 6(a)), while expression of Pck1 was similar between the obese mice (Figure 6(b)). Expression of acetyl co-A carboxylase 1 was 2.7 -fold higher in $d b / d b$ mice relative to mice fed a WD (Figure 6(c)), while expression of fatty acid synthase (Figure 6(d)) and stearoyl co-A desaturase 1 (Figure 6(e)) were similar between the mice. Consistent with the elevated levels of acetyl co-A carboxylase 

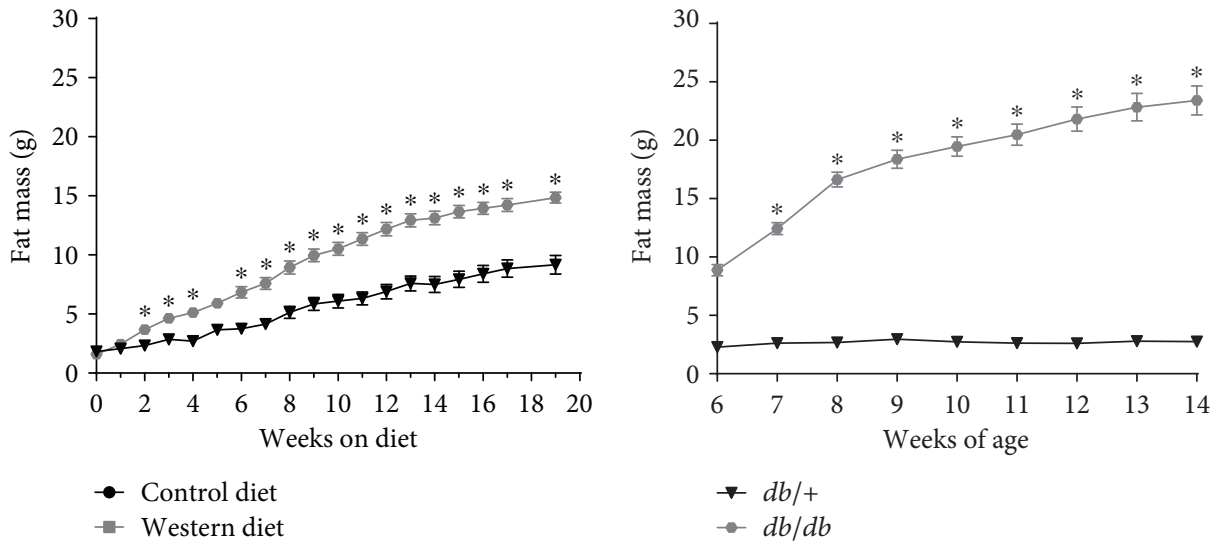

(a)
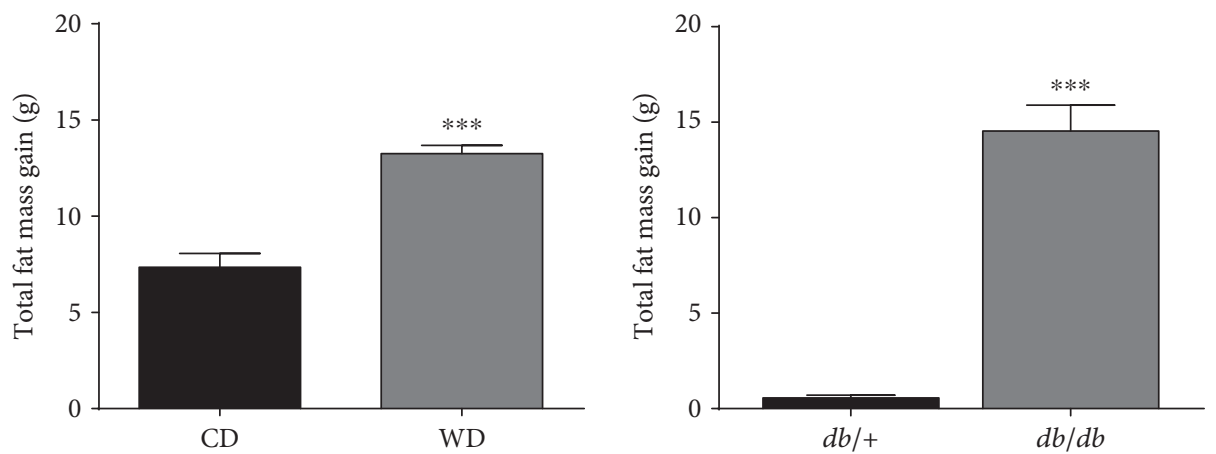

(c)

(d)

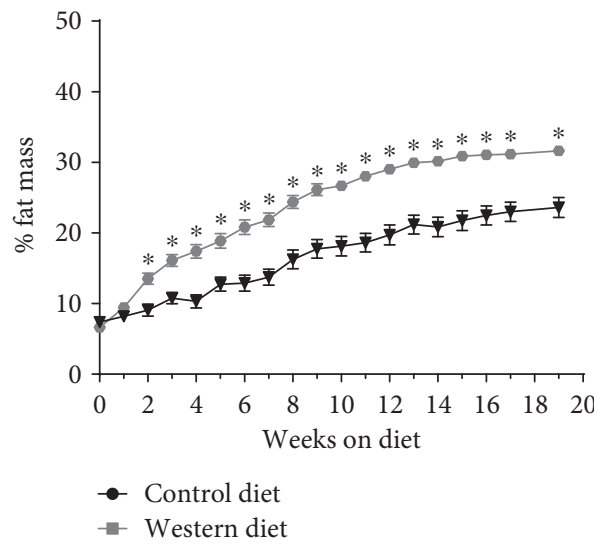

(e)

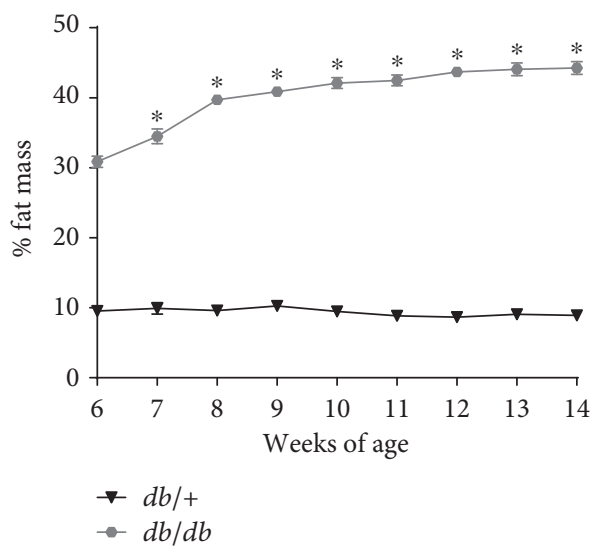

$(\mathrm{f})$

Figure 2: Increased fat mass occurs in both diet-induced and genetically driven forms of obesity. Fat mass (a) and \% fat mass (e) in male C57BL/6J mice fed either control or Western diet for 20 weeks. Total fat mass gain (c) at the end of the 20-week feeding period. Fat mass (b) and \% fat mass (f) in male $d b /+$ and $d b / d b$ mice between 6 and 14 weeks of age. Total fat mass gain by 14 weeks of age (d). For fat mass measurements, $y$-axes are set to the same scale for comparison between study groups. $n=8$ per group; means \pm SEM; ${ }^{* * *} p<0.001$ versus control; ${ }^{*} p<0.05$ versus control by repeated measures ANOVA. CD: control diet; WD: Western diet.

mRNA, we found that total liver acyl glycerols (mono-, di-, and tri-glycerols) were $57 \%$ higher in $d b / d b$ mice relative to mice consuming the WD (Figure 6(f)). Relevant to corticosterone metabolism, the livers of WD-fed mice and $d b / d b$ mice showed similar expression of the hsd11b1 gene, which encodes the enzyme 11beta-hydroxysteroid dehydrogenase 1 (Figure 6(g)). However, expression of the hsd11b2 gene was markedly reduced in $d b / d b$ mice relative to mice fed the WD (Figure 6(h)).
3.6. There Is Reduced Skeletal Muscle Fat Oxidation in WDFed Mice, While Derangements in Both Skeletal Muscle and Liver Fat Oxidation Are Present in Weight-Matched db/db Mice. A trait observed during obesity-associated insulin resistance is the development of metabolic inflexibility, which is defined as the inability to appropriately transition between different fuel sources [28]. To test whether or not differences in metabolic flexibility occur at the tissue level in the diet-induced and genetic models of obesity, we used 

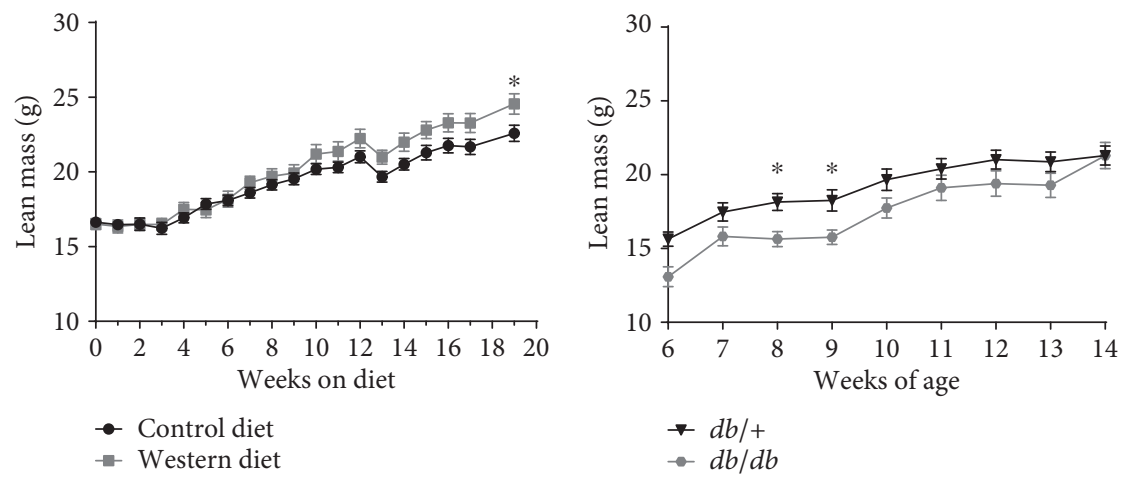

(a)

(b)
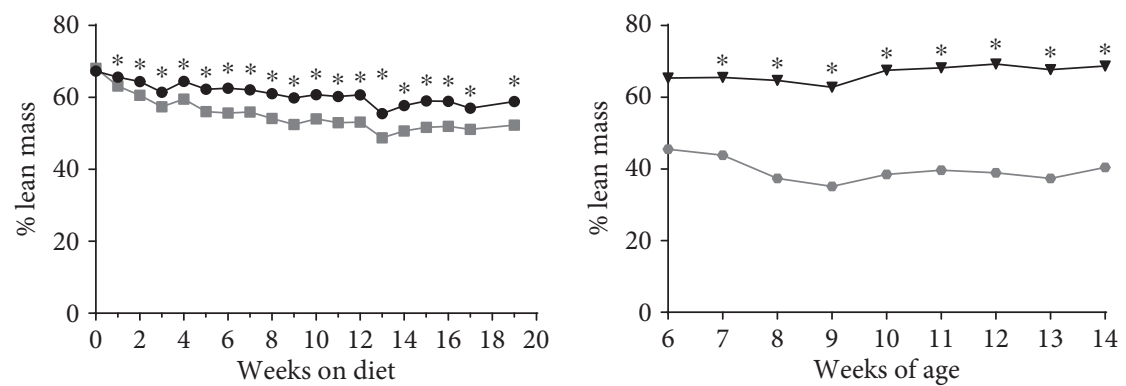

- Control diet

- Western diet

$\rightarrow d b /+$

$-d b / d b$

(c)

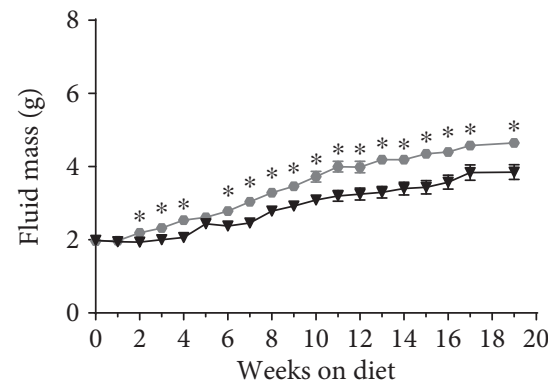

(d)

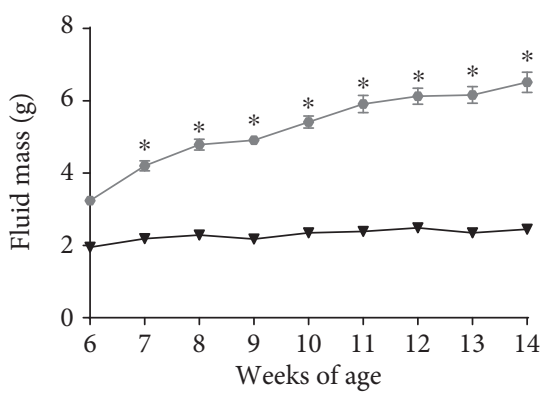

$\rightarrow d b /+$

$-d b / d b$

(e)

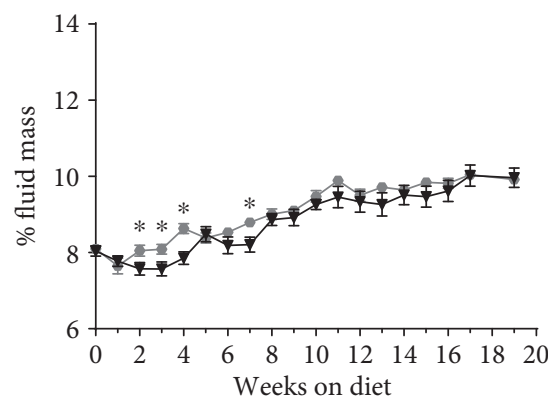

$\rightarrow$ Control diet

- Western diet

(g)

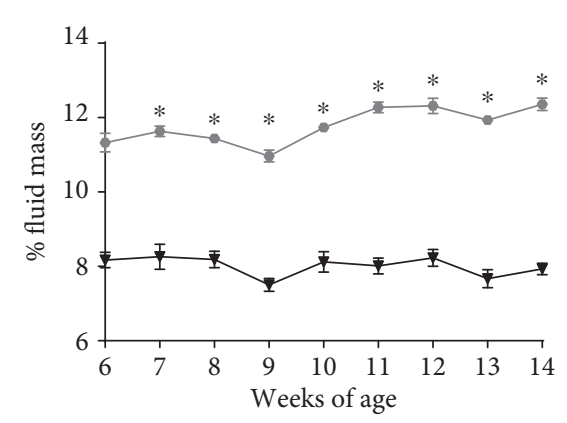

$\rightarrow d b /+$

- $d b / d b$

(h)

FIGURE 3: Lean and fluid mass profiles in WD-fed and genetically obese $d b / d b$ mice. Lean mass (a), \% lean mass (c), fluid mass (e), and \% fluid mass (g) in male C57BL/6J mice fed either control or Western diet for 20 weeks. Lean mass (b), \% lean mass (d), fluid mass (f), and \% fluid mass (h) in male $d b /+$ and $d b / d b$ mice between 6 and 14 weeks of age. $n=8$ per group; means \pm SEM; ${ }^{*} p<0.05$ versus control by repeated measures ANOVA. 


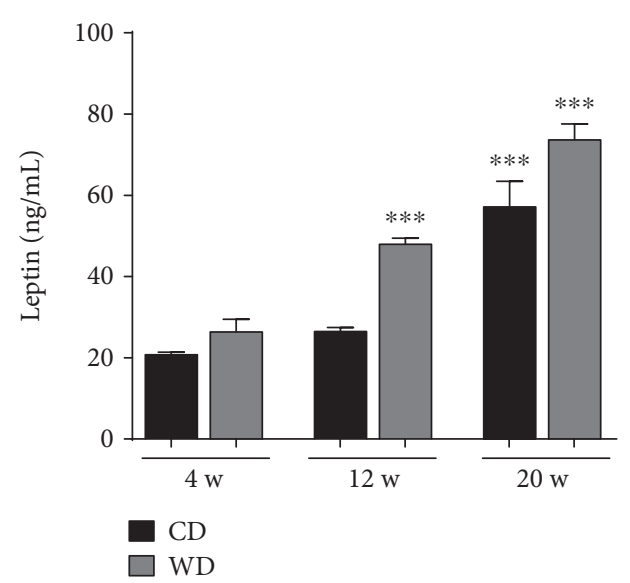

(a)

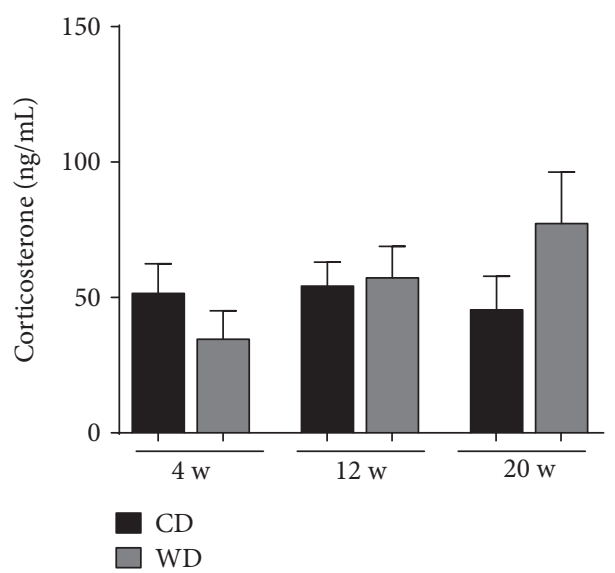

(c)

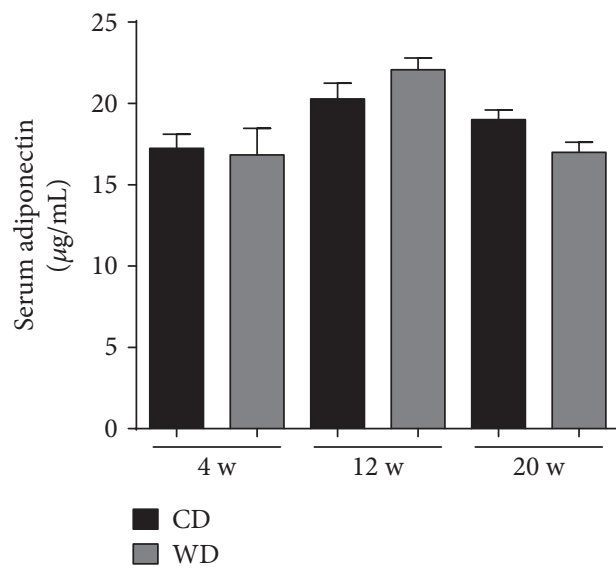

(e)

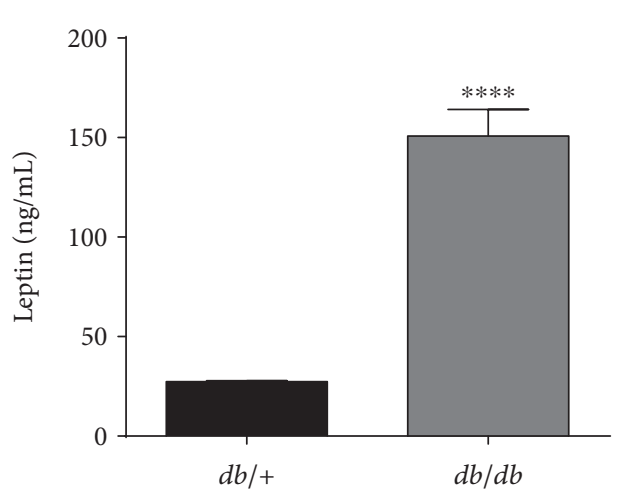

(b)

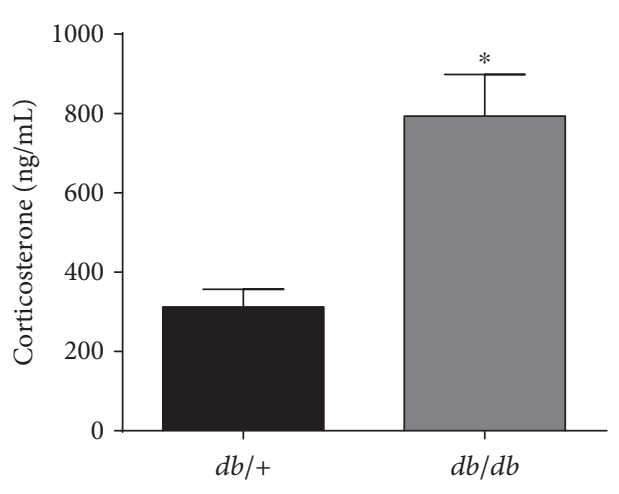

(d)

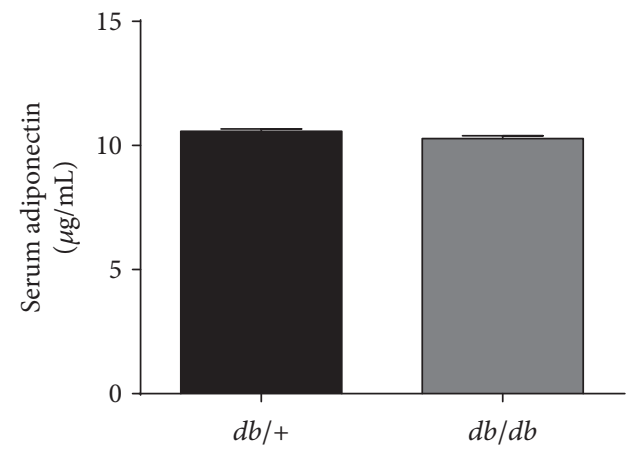

(f)

Figure 4: Elevated corticosterone in serum of $d b / d b$ mice but not WD-fed mice. Serum levels of leptin (a, b), corticosterone (c, d), and adiponectin (e, f) in C57BL/6J mice fed either control or Western diet for 4, 12, and 20 weeks (a, c, e) or 14-week-old $d b /+$ and $d b / d b$ mice (b, d, f). $n=8$ per group; means \pm SEM. ${ }^{* * * *} p<0.0001 ;{ }^{* * *} p<0.001 ;{ }^{*} p<0.05$. CD: control diet; WD: Western diet; HFD.

mixed gastrocnemius (MG) skeletal muscle and liver homogenates to measure fatty acid oxidation under conditions designed to test substrate selection (Figure 7). Compared to mice fed a control diet, MG from mice fed a Western diet had no difference in complete $\left(\mathrm{CO}_{2}\right)$ palmitate oxidation
(Figure 7(a)); however, MG from these mice did have elevated incomplete fatty acid oxidation rates (i.e., acid soluble metabolites (ASM); see Figure 7(b)). Alternatively, MG from $d b / d b$ mice revealed higher baseline complete (Figure 7(e)) and incomplete (Figure 7(f)) palmitate oxidation than the 


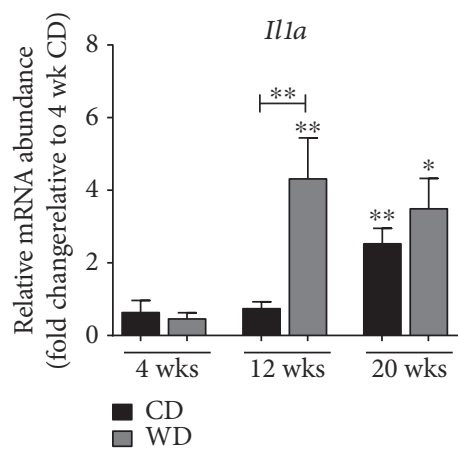

(a)

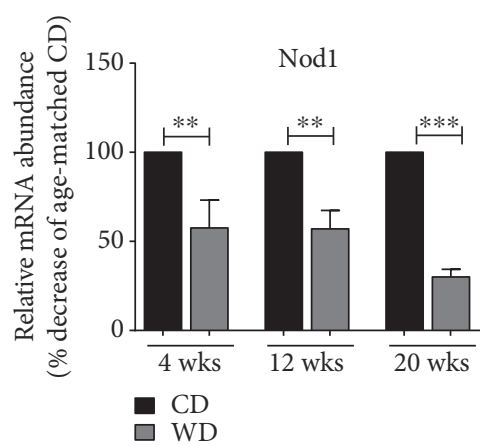

(c)

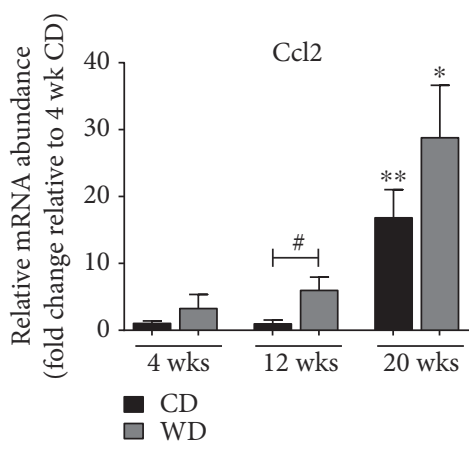

(e)

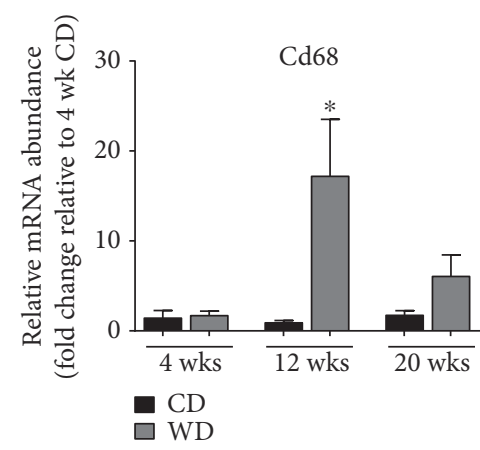

(g)

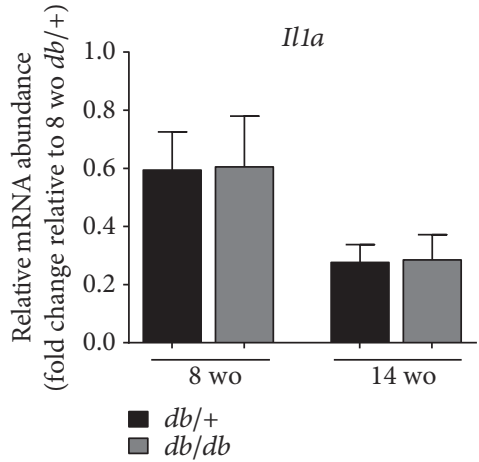

(b)

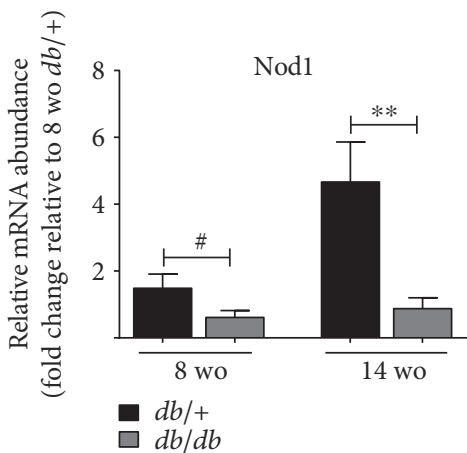

(d)

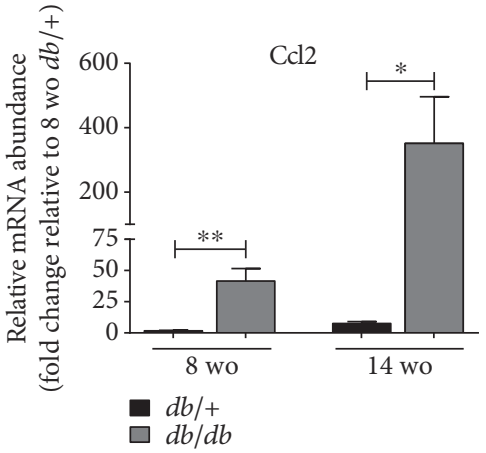

(f)

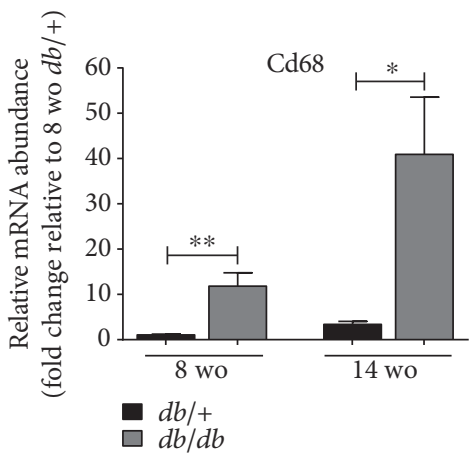

(h)

FIGURE 5: Increased expression of inflammatory markers is evident in epididymal adipose tissue from both genetic and diet-induced obesity. Relative mRNA abundance of the inflammatory genes $\operatorname{Illa}(\mathrm{a}, \mathrm{b}), \operatorname{Nod} 1$ (c, d), Ccl2 (e, f), and Cd68 (g, h) in epididymal adipose tissue from either C57BL/6J mice fed either control or Western diet for 4, 12, and 20 weeks (a, c, e, g) or 8- and 14-week-old $d b /+$ and $d b / d b$ mice (b, d, f, h). $n=8$ per group. Data are normalized to the reference gene Ppia and are represented as means \pm SEM. ${ }^{* * *} p<0.001$; ${ }^{* *} p<0.01 ;{ }^{*} p<0.05$; ${ }^{\#} p<0.1$ by one-way ANOVA with Tukey's post hoc analysis. (a), (e), and (g) $p$ values versus respective 4 -week dietary group unless denoted by bar. CD: control diet; WD: Western diet; wo: weeks old. 


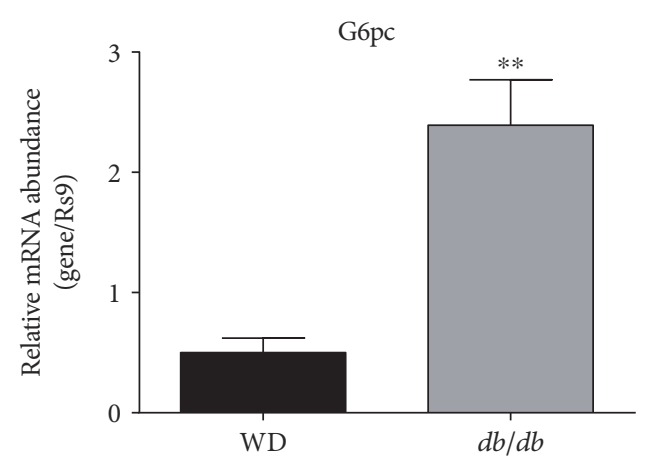

(a)

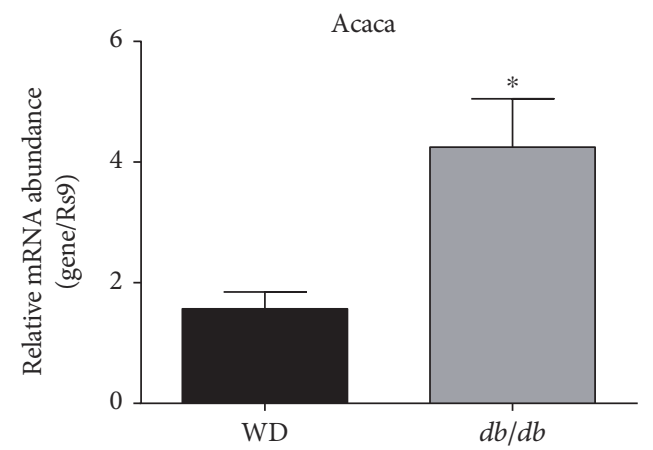

(c)

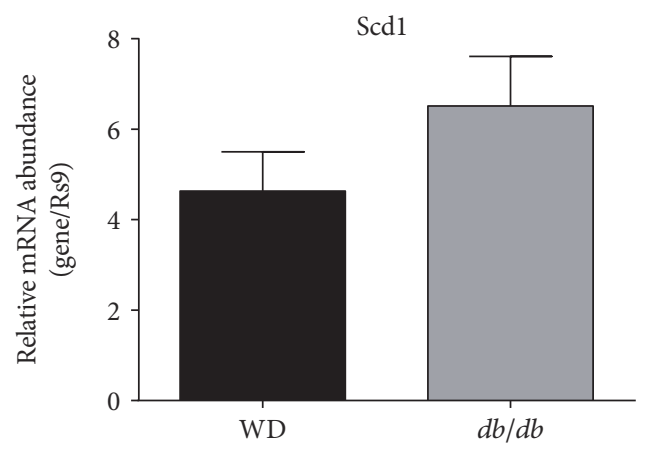

(e)

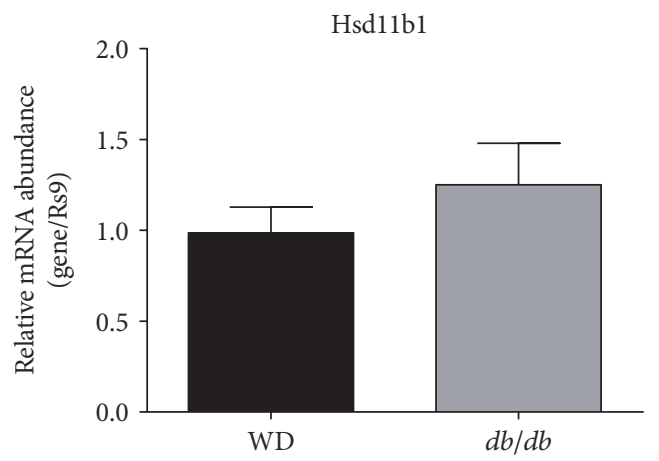

(g)

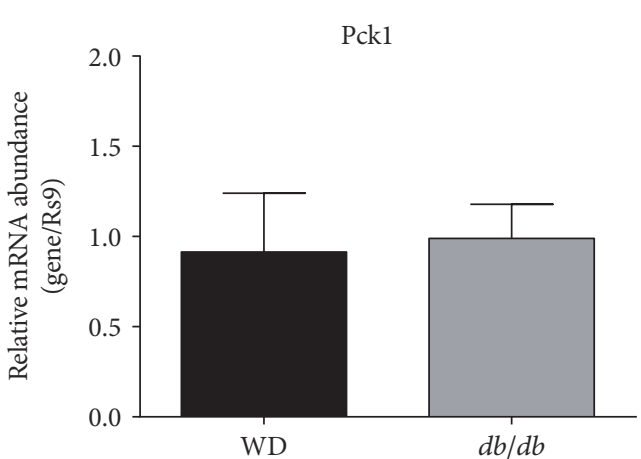

(b)

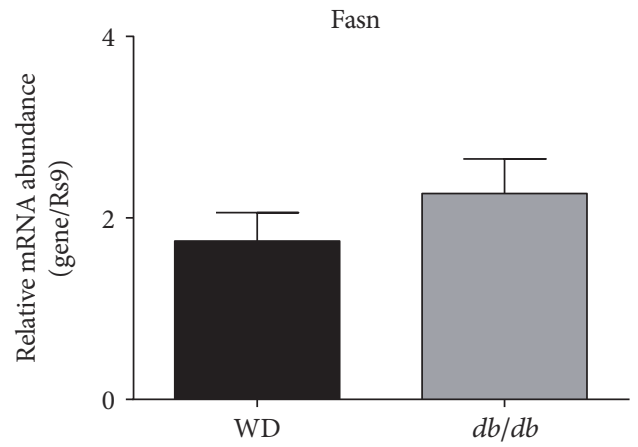

(d)

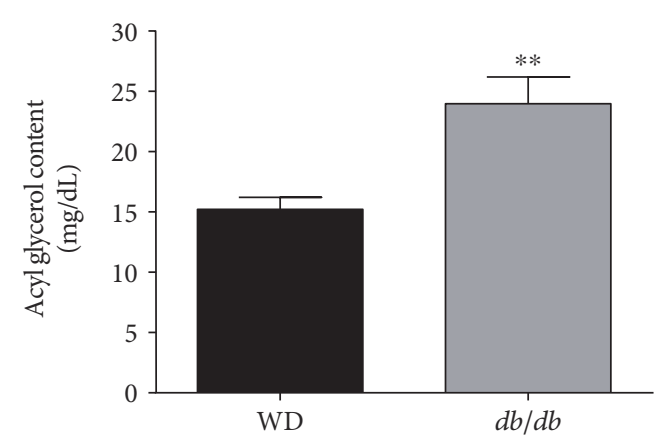

(f)

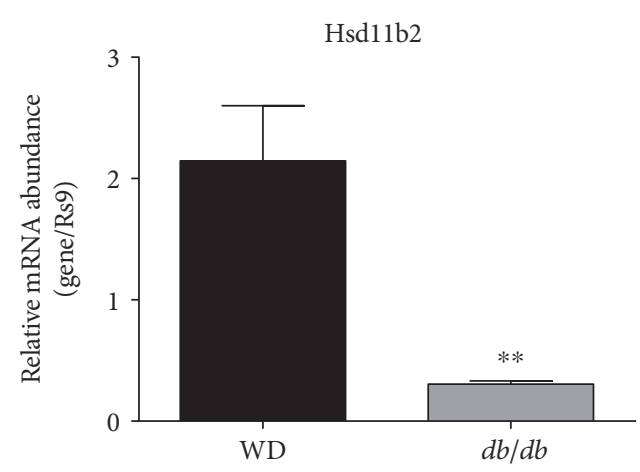

(h)

FIGURE 6: Livers from $d b / d b$ mice displayed enhanced expression of glucose 6-phosphatase, acetyl Co-A carboxylase, and elevated acyl glycerol content when compared with livers from WD-fed mice. Relative mRNA abundance of the G6pc (a), Pck1 (b), Acaca (c), Fasn (d), Scd1 (e), Hsd11b1 (g), and Hsd11b2 (h) genes in the liver tissue from either C57BL/6J mice fed either Western diet for 20 weeks (black panels) or 14-week-old $d b / d b$ mice (gray panels). Acyl glycerol content (f) was quantified using 30 mg of liver tissue from either Western diet-fed C57BL/6J mice (20 weeks on diet; black panels) or 14 -week-old $d b / d b$ mice (gray panels). $n=8$ per group. Data are represented as means \pm SEM. ${ }^{* *} p<0.01 ;{ }^{*} p<0.05$. 
$\mathrm{CO}_{2}$

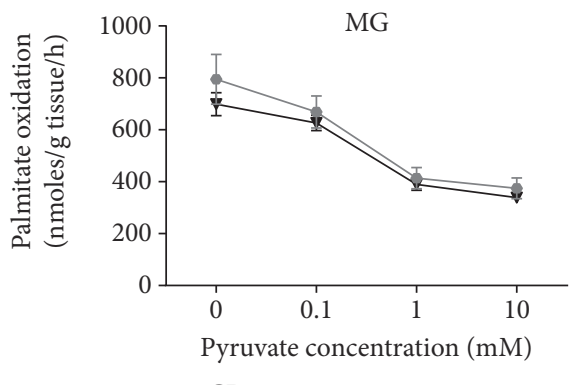

(a)

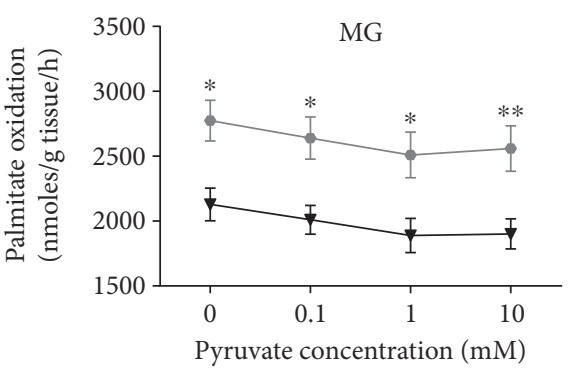

$\rightarrow$ CD $20 \mathrm{w}$

$\rightarrow$ WD $20 \mathrm{w}$

(b)

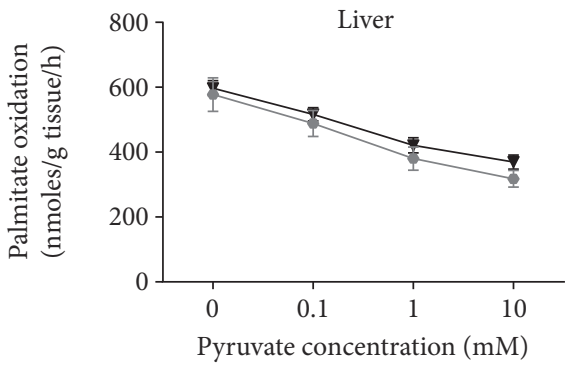

$\rightarrow$ CD $20 \mathrm{w}$

$\rightarrow$ WD $20 \mathrm{w}$

(c)

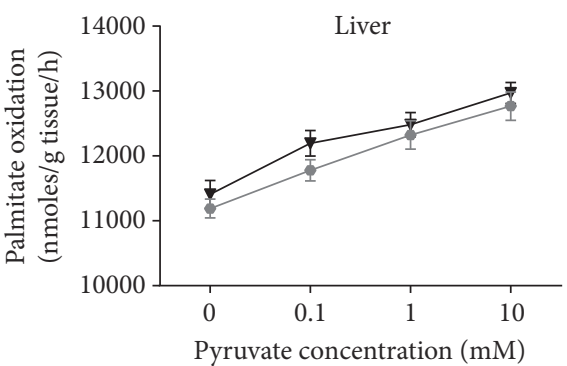

$\rightarrow$ CD $20 \mathrm{w}$

- WD $20 \mathrm{w}$

(d)

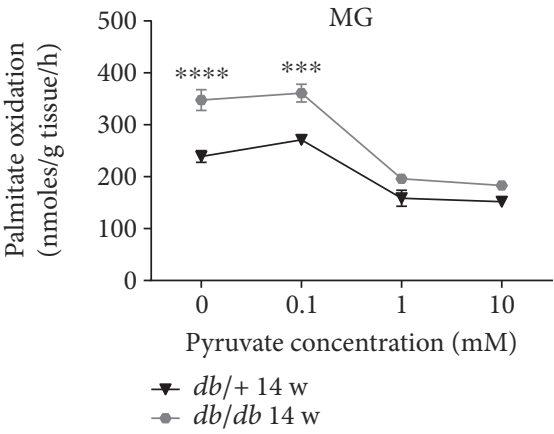

(e)

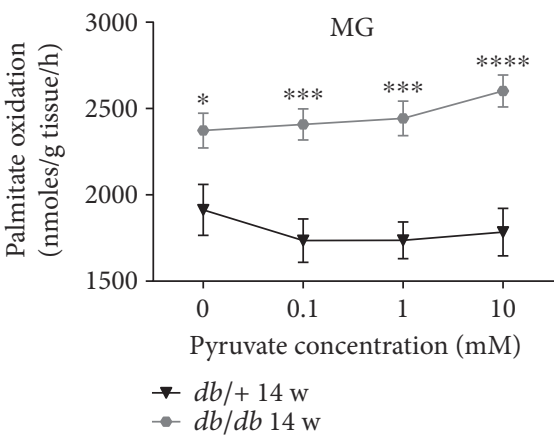

(f)

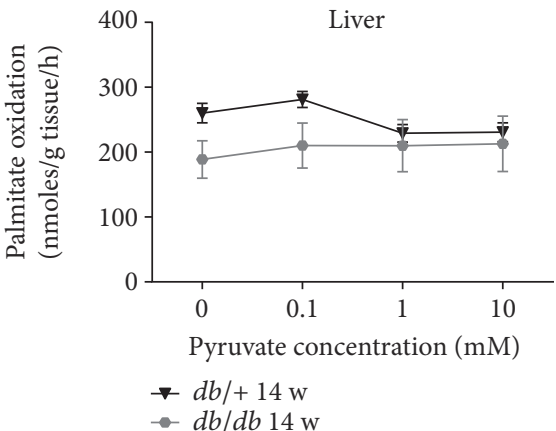

(g)

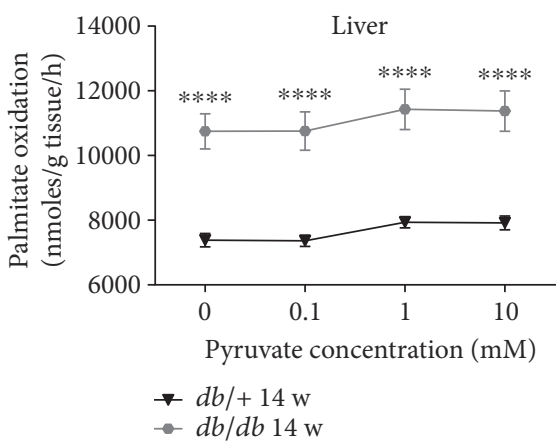

(h)

FIGURE 7: Derangements in the skeletal muscle and liver fat oxidation occur in $d b / d b$ mice, while diet-induced obesity only negatively impacts skeletal muscle fat oxidation. Using $\left[1-{ }^{14} \mathrm{C}\right]$ palmitate $(100 \mu \mathrm{M})$, substrate switching was assessed by measuring complete $\left(\mathrm{CO}_{2}\right)$ and incomplete (acid soluble metabolite (ASM)) fat oxidation \pm varying doses of pyruvate as a competing substrate. Assays were run using homogenates from mixed gastrocnemius (MG) skeletal muscle ( $\mathrm{a}, \mathrm{b}, \mathrm{e}, \mathrm{f})$ and liver $(\mathrm{c}, \mathrm{d}, \mathrm{g}, \mathrm{h})$ from diet-induced (control diet versus Western diet for 20 weeks; a-d) and a genetically obese model ( $d b /+$ versus $d b / d b$ mice aged 14 weeks; e-h) of obesity. $n=8$ per group; means \pm SEM. ${ }^{* * * *} p<0.0001$ versus control; ${ }^{* * *} p<0.001$ versus control; ${ }^{* *} p<0.01$ versus control; ${ }^{*} p<0.05$ versus control by two-way repeated measures ANOVA with Bonferroni post hoc test for multiple comparisons. 
lean $\mathrm{db} /+$ controls. Interestingly, the rates of $\mathrm{CO}_{2}$ production from both $d b /+$ and $d b / d b$ mice are distinctly lower than C57BL6/J mice fed either a control or Western diet (Figure $7(\mathrm{a}))$. Importantly, palmitate oxidation rates $\left(\mathrm{CO}_{2}\right.$ and ASM) in MG from both models of obesity had a main effect for pyruvate concentration indicating substrate switching; however, only genetically obese mice had an interaction effect $\left(\mathrm{CO}_{2} p=0.0054\right.$; ASM $\left.p=0.0005\right)$, indicating $d b / d b$ mice exhibit a different substrate switching effect than their lean $d b /+$ counterparts. Moreover, mice fed the control diet and Western diet (Figure 7(b)), as well as $d b /+$ mice (Figure 7(f)), all exhibit a decrease in ASM production as pyruvate concentrations increase. However, $d b / d b$ mice have a contrasting rise in incomplete palmitate oxidation under the same conditions (Figure 7(f)).

In the liver, feeding a Western diet did not alter complete (Figure $7(\mathrm{c})$ ) or incomplete (Figure $7(\mathrm{~d})$ ) palmitate oxidation. By contrast, the liver from $d b / d b$ mice have slightly lower basal $\mathrm{CO}_{2}$ production (Figure $7(\mathrm{~g})$ ) and clearly demonstrate substantially exaggerated incomplete fat oxidation (Figure $7(\mathrm{~h})$ ). As pyruvate concentrations were increased, an interaction effect was observed for complete palmitate oxidation $(p=0.0048)$ indicating the $d b / d b$ mice had virtually a complete lack of substrate switching compared to $d b /$ + controls (Figure $7(\mathrm{~g})$ ). Alternatively, no interaction effect was found concerning ASM production, indicating the impact of increasing pyruvate levels on incomplete hepatic fat oxidation was similar between $d b /+$ and $d b / d b$ mice (Figure $7(\mathrm{~h}))$. It is notable that $d b /+$ and $d b / d b$ mice have lower complete hepatic palmitate oxidation rates, as well as reduced pyruvate-induced shift in hepatic fatty acid oxidation $\left(\mathrm{CO}_{2}\right.$ and $\left.\mathrm{ASM}\right)$ than C57BL6/J mice fed either a control or Western diet (Figure 7).

3.7. Circulating Insulin Levels Are Elevated in Both Models of Obesity, but Glucagon Is Only Increased in the db/db Mice. Hyperinsulinemia is present during obesity and is an independent risk factor for human disease $[29,30]$. When analyzing this parameter in the obese mouse models, we found 2.5-, 2.6- and 3-fold increases in circulating levels of insulin at 4, 12, and 20 weeks, respectively, in WD-fed C57BL/6J mice compared to mice fed the control diet (Figure 8(a)). By comparison, $d b / d b$ mice have 15.1-fold more insulin in circulation than their $d b /+$ counterparts (Figure 8(b)) at 14 weeks of age. Serum insulin levels strongly correlated with both total body mass (Figures $8(\mathrm{c})$ and $8(\mathrm{~d})$ ) and fat mass (Figures $8(\mathrm{e})$ and $8(\mathrm{f})$ ) in both diet-induced and genetic mouse models of obesity. In contrast to insulin, glucagon levels are unchanged in WD versus $\mathrm{CD}$ at 12 and 20 weeks of feeding (Figure $8(\mathrm{~g})$ ), while $d b / d b$ mice displayed $87 \%$ more circulating glucagon when compared to the lean $d b /+$ control mice (Figure 8(h)).

3.8. The Islets of db/db Mice, but Not Western Diet-Fed Mice, Display Markers of Dedifferentiation. Insulin resistance drives increases in pancreatic islet $\beta$-cell mass [9]. Therefore, we next examined islet architecture between WD-fed mice and $d b / d b$ mice. Both models of obesity display increases in insulin positive area over lean control mice (Figure 9).
However, islets from $d b / d b$ mice display clear evidence of glucagon-positive cells within the core of the islet, which was not regularly observed in mice fed the WD (Figure 9(a)). This is consistent with an increase in glucagon transcripts within islets of $d b / d b$ mice relative to WD-fed mice (not shown) and an increase in circulating glucagon in $d b / d b$ mice (Figure 8(h)). In addition, we observed less immunoreactive Nkx6.1 in the nuclei of the $d b / d b$ islets, which is consistent with pancreatic islets from humans with T2D [14]. By contrast, the islets of WD-fed mice retained strong evidence of nuclear Nkx6.1 expression (Figure 10(a)). Furthermore, Aldh $1 \mathrm{a} 3$ expression was markedly elevated in $d b / d b$ islets when compared with islets from WD-fed mice (Figure 10(b)). The increase in transcript is congruent with the increase in immunoreactive Adh1a3 in islets from $d b / d b$ mice, but not in WD-fed C57BL/6J mice (Figure 10(c)). Taken together, these data are consistent with the premise that WD-fed mice display features of insulin resistance (e.g., islet mass expansion), while islets from $d b / d b$ mice display features of T2D (e.g., elevated glucagon and indicators of dedifferentiation).

\section{Discussion}

There are many important signs and symptoms that indicate risk for the eventual development of T2D, including obesity, inflammation, insulin resistance, and hyperinsulinemia $[4,5,30,31]$. The use of mouse models is important for understanding the specific pathways contributing to alterations in tissue function, insulin sensitivity, islet hormone production, $\beta$-cell proliferation, insulin resistance, and overall glucose homeostasis. Therefore, we compared two distinct models of obesity in mice, the Western diet-fed C57BL/6J mouse and the $d b / d b$ mouse on the C57BL/6J genetic background. The results presented in this study have led us to conclude that in mice with similar body weights, the WDfed C57BL/6J mouse is an excellent model of early features representing the human prediabetic condition, while the $d b / d b$ mouse more closely resembles human T2D.

Elevations in circulating insulin were evident within four weeks after introduction of the WD to mice (Figure 8(a)). These data are consistent with hyperinsulinemia in $d b / d b$ mice (Figure $8(\mathrm{~b})$ ) and observations in the human population [32]. The present findings are important because hyperinsulinemia is a risk factor for many, if not all, symptoms used to denote the metabolic syndrome [33-35]. These conditions are readily recapitulated in the WD-fed mouse model and in the genetically obese $d b / d b$ mice. In addition, elevated insulin levels have been suggested to be a causal factor for obesity $[36,37]$. The idea that insulin influences body weight and overall adiposity is consistent with the correlations calculated for circulating insulin with total body mass (Figures 8(c) and 8(d)) and fat mass (Figures 8(e) and 8(f)) in both WD-fed and genetically obese $d b / d b$ mice. Moreover, reducing insulin levels, by using diazoxide to decrease $\beta$-cell insulin output, restricts body weight in rodents by enhancing metabolic rate and increasing fat oxidation [38].

Human twin studies demonstrate that obesity has a significant genetic component [39]. In addition, there is 


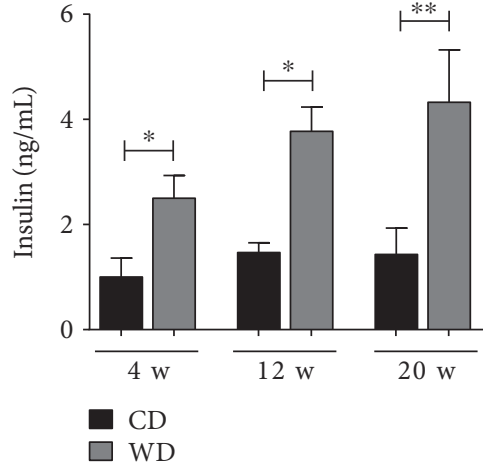

(a)

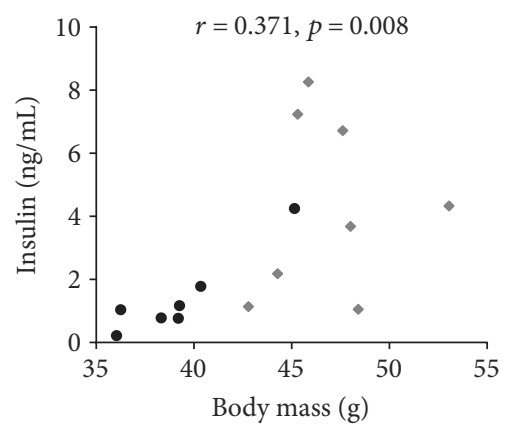

(c)

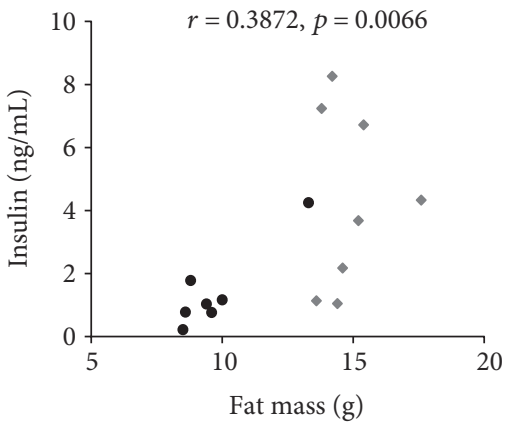

(e)

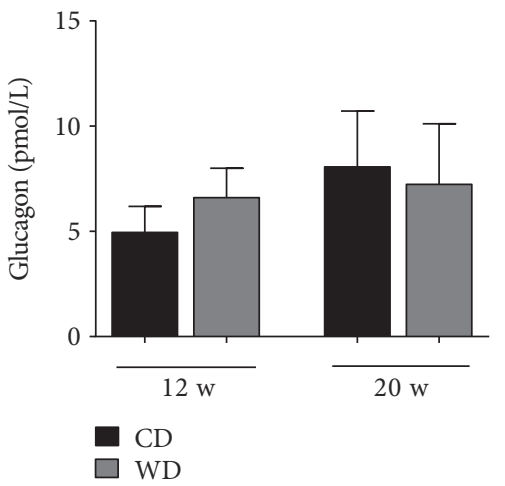

(g)

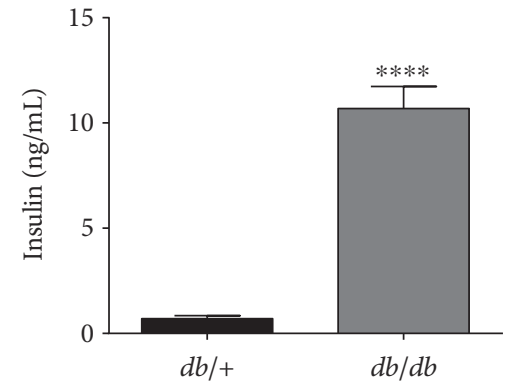

(b)

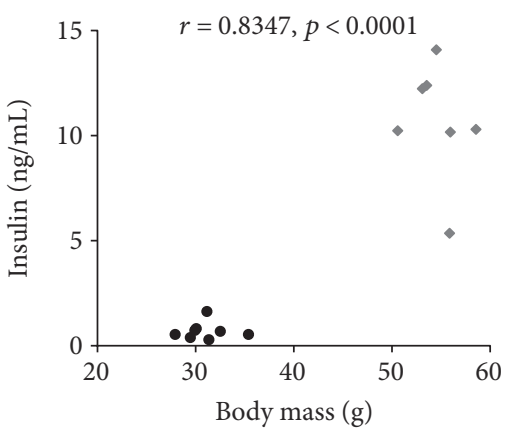

(d)

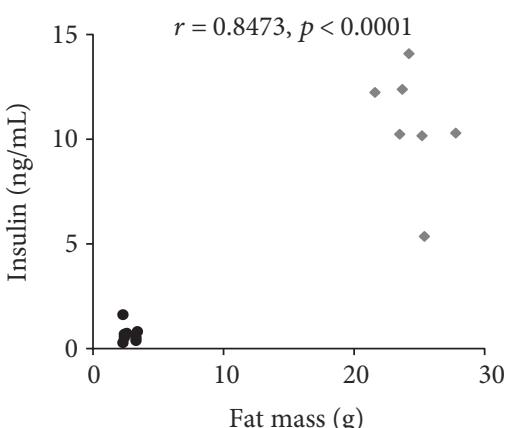

(f)

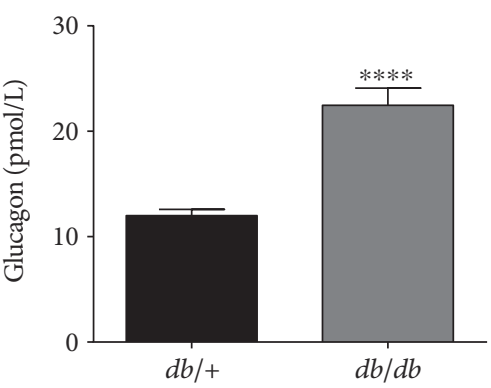

(h)

FIGURE 8: Circulating insulin levels are elevated in both mouse models of obesity, but glucagon is increased only in the $d b / d b$ mice. Serum insulin $(\mathrm{a}, \mathrm{b})$ and glucagon $(\mathrm{g}, \mathrm{h})$ in C57BL/6J mice fed either control or Western diet for the indicated number of weeks (a, g) or 14week-old $d b /+$ and $d b / d b$ mice $(b, h)$. Serum insulin correlated to body mass or fat mass in C57BL/6J mice fed Western diet for 20 weeks (c and e, resp.) and in 14-week-old $d b / d b$ mice ( $\mathrm{d}$ and $\mathrm{f}$, resp.) by Spearman's correlation. $n=8$ per group; means \pm SEM; ${ }^{* * * *} p<0.0001$; ${ }^{* *} p<0.01 ;{ }^{*} p<0.05$. CD: control diet; WD: Western diet. 
Body weight (g): 48

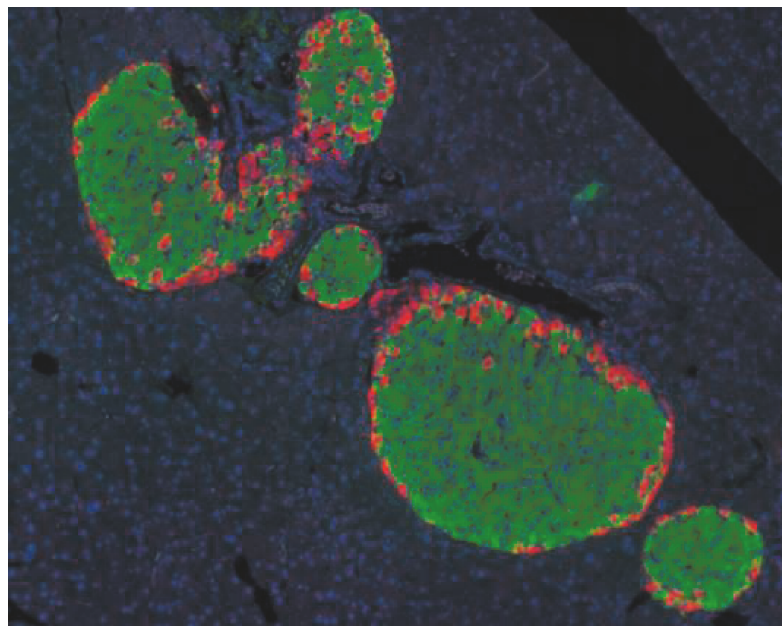

(a)

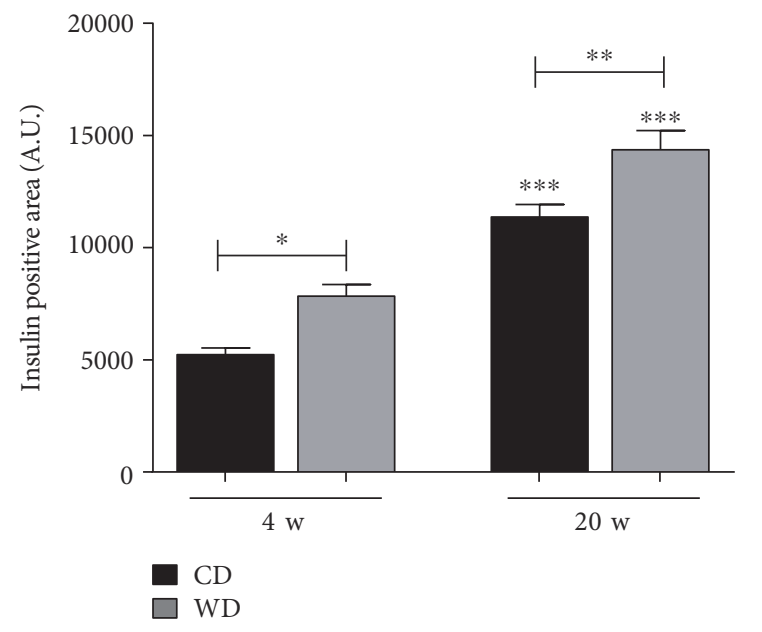

(b)

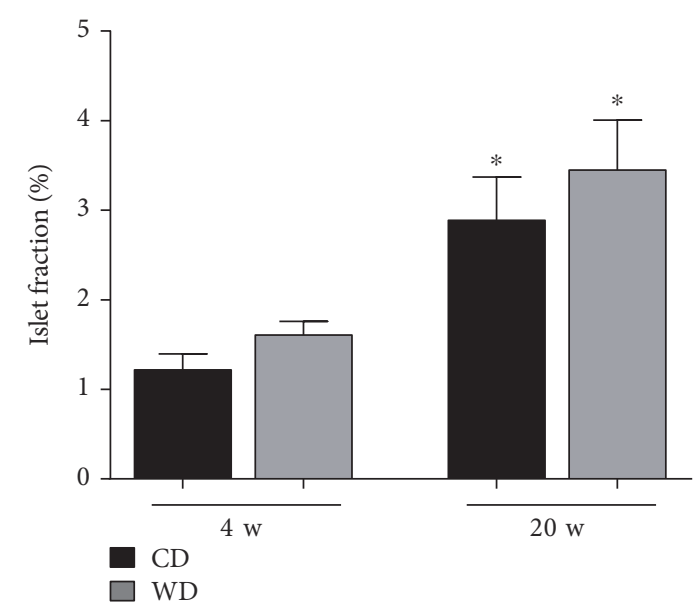

(d)
Body weight (g): 50
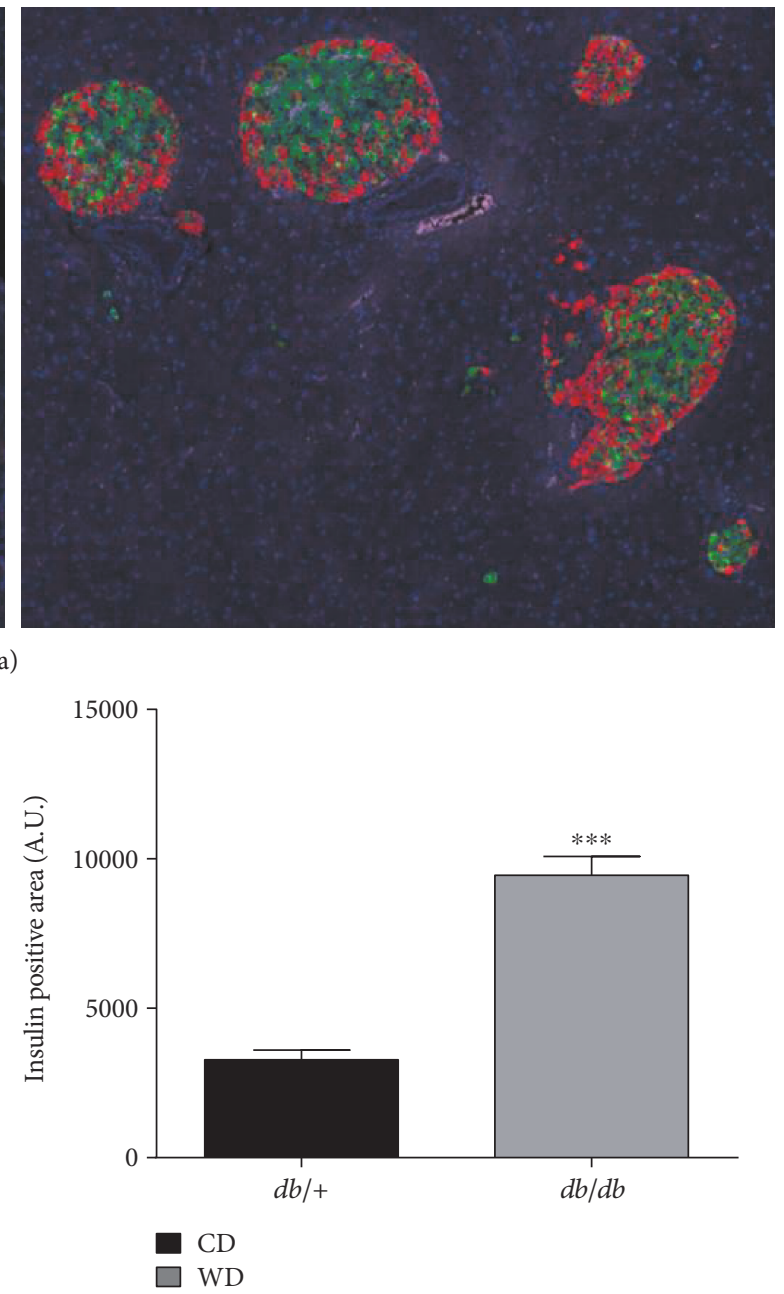

(c)

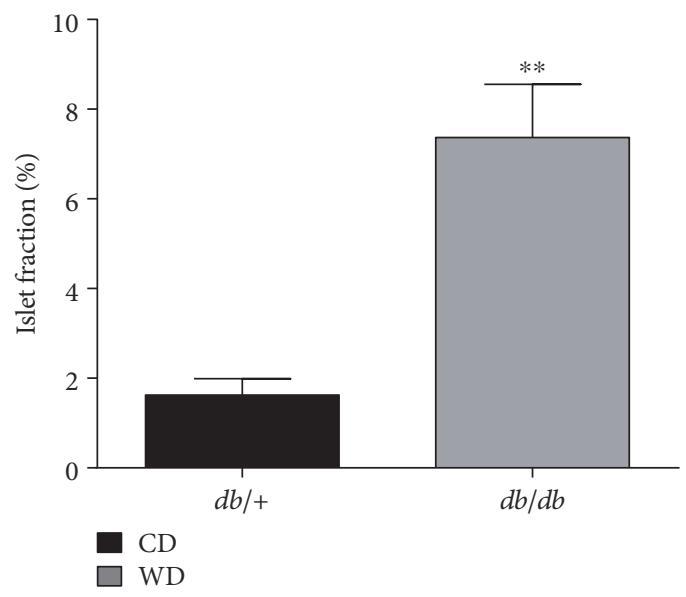

(e)

FIGURE 9: Islet size and insulin-positive area increase in both $d b / d b$ and WD-fed mice. (a) Immunofluorescent images from pancreatic sections stained for insulin (green), glucagon (red), and DAPI nuclear stain (blue) from C57BL/6J fed WD for 20 weeks (left panel) or 14week-old $d b / d b$ mice (right panel). Insulin-positive area (b and $\mathrm{c}$ ) and calculations of islet area relative to total pancreatic area, that is, islet fraction ( $\mathrm{d}$ and e) are shown for C57BL/6J mice fed either control or Western diet for 4 or 20 weeks (b, d) and 14-week-old $d b /+$ compared with $d b / d b$ mice (c, e). Insulin-positive area and islet fraction were quantified using 8 mice per group. Data are shown as mean \pm S.E.M. ${ }^{* * *} p<0.001 ;{ }^{* *} p<0.01 ;{ }^{*} p<0.05$. CD: control diet; WD: Western diet. 

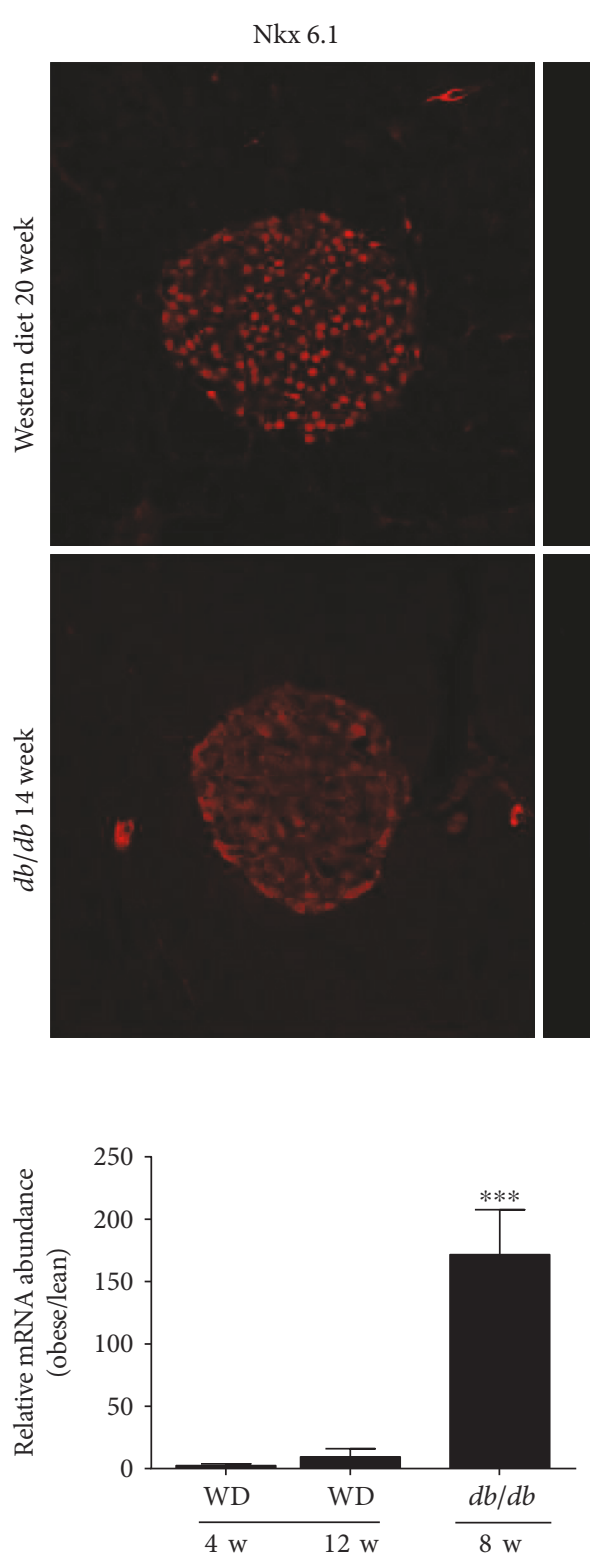

(b)
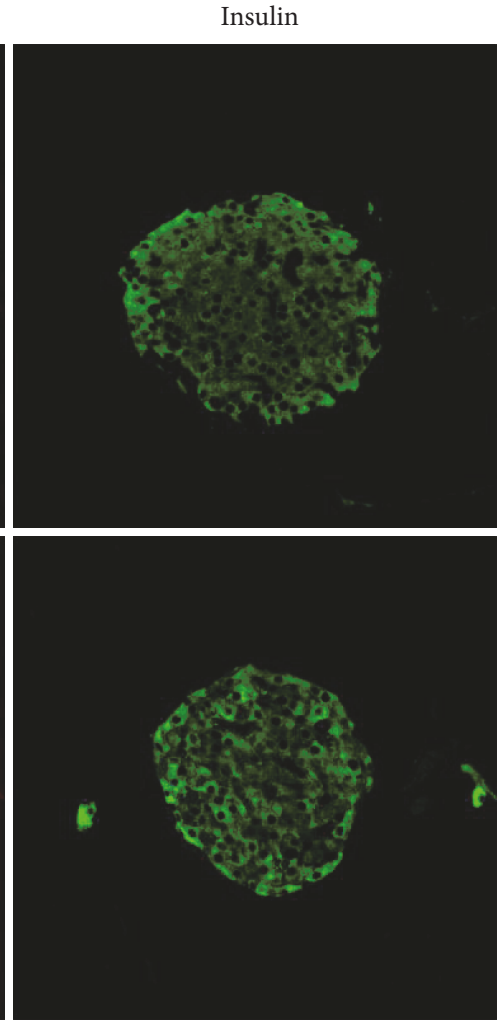

(a)

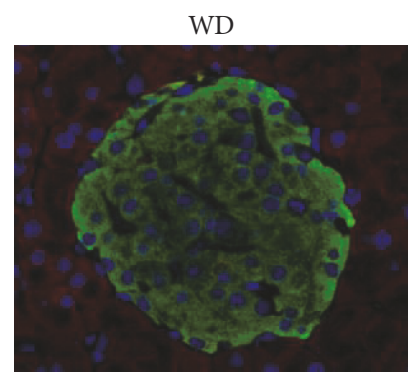

(c)
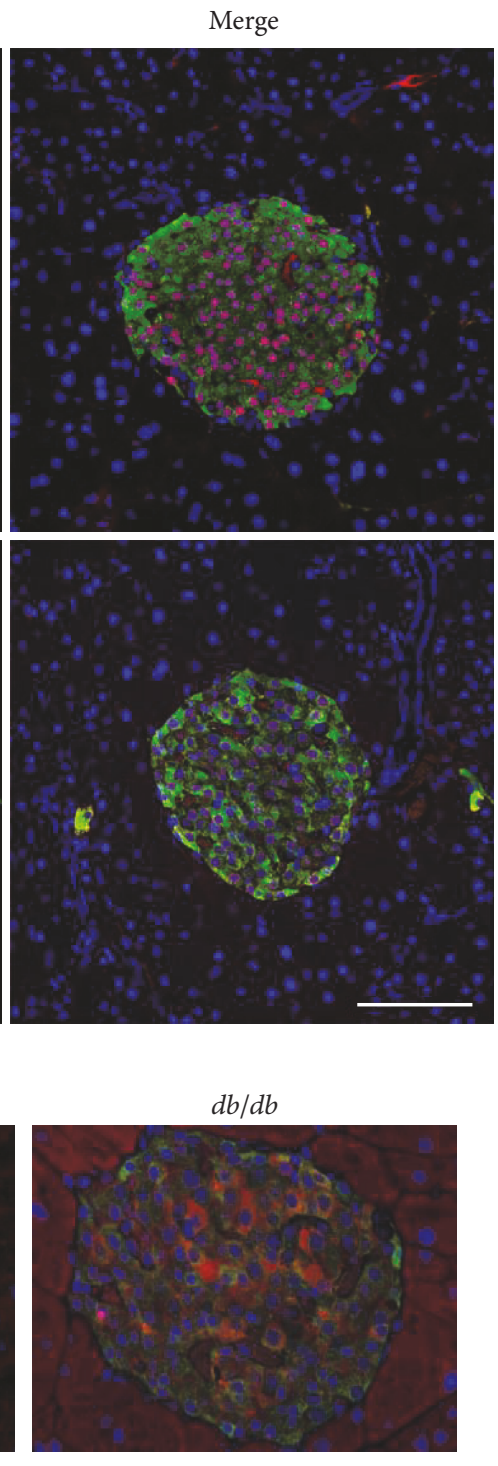

FIgURE 10: Markers of dedifferentiation are present in islets of $d b / d b$, but not weight-matched WD-fed mice. (a) Immunofluorescent analysis of islets from weight-matched WD-fed mice (top row) and $d b / d b$ mice (bottom row) showing Nkx6.1 (red), insulin (green), and DAPI (blue). In the merged image, note the loss of double-positive nuclei (DAPI plus Nkx6.1; purple color) in the $d b / d b$ mice but not in the WD-fed mice. (b) Expression of the Aldh1a3 gene in islets isolated from mice fed a WD for 4 or 12 weeks normalized to mice fed a control diet compared with $d b / d b$ mice at 8 weeks of age (normalized to lean $d b /+$ controls). ${ }^{* * *} p<0.001$ versus both WD groups by one-way ANOVA. (c) Staining for Aldhla3 protein (red) and insulin (green) in islets from weight-matched WD-fed mice (20 weeks on diet) versus $d b / d b$ mice (14 weeks of age).

evidence that islet $\beta$-cell failure, which is required for progression to $\mathrm{T} 2 \mathrm{D}$, also has a genetic basis [40]. Indeed, mutations in genes important for adult $\beta$-cell phenotype, such as GLUT2, glucokinase, NeuroD/beta2, HNF1/4, and Nkx6.1, contribute to deterioration of $\beta$-cell function in human T2D [41]. In our analyses of islets from mice fed a WD versus islets from $d b / d b$ mice, we found that Nkx6.1 is reduced or absent from the nuclei of $\beta$-cells in the islets of $d b / d b$ mice (Figure 9(a)). Nkx6.1 plays a key role in negatively controlling expression of the glucagon gene and therefore maintaining islet $\beta$-cells in a mature, fully differentiated state $[15,16]$.

The reduction in nuclear Nkx6.1 that we observe in $d b / d b$ islets is also consistent with findings in pancreatic tissue from Zucker diabetic fatty rats [42] and in human subjects with T2D [14]. The increase in glucagon-positive cells we found in $d b / d b$ islets (Figure 9(a)) connects changes in the pancreatic islets with the enhanced circulating glucagon in these mice (Figure $8(\mathrm{~h})$ ). Moreover, these data are congruent with reductions in Nkx6.1 transcripts (see [18]) and nuclear 
protein abundance in the islets of $d b / d b$ mice (Figure 10(a)). Importantly, our findings are relevant to human disease because hyperglucagonemia is a key feature of the diabetic state $[17,43,44]$. Insulin resistance in pancreatic alpha cells may explain the elevations in circulating glucagon observed in $d b / d b$ mice. Furthermore, deletion of glucagon receptors prevents hyperglycemia in obese mice with elevated glucagon [45]. We also see increases in Aldh1a3 transcript and protein in $d b / d b$ islets (Figures $10(b)$ and $10(c)$ ), a recently identified marker of dysfunctional and/or dedifferentiated $\beta$-cells [46]. Aldh1a3 is not elevated in the islets from WD-fed mice (Figures 10(b) and 10(c)) or any of the lean control mice (not shown), which supports our interpretation that $d b / d b$ mice display phenotypes consistent with human T2D while WD-fed C57BL/6 mice may represent an earlier, nondiabetic stage of obesity and insulin resistance.

A metabolic signature of insulin-resistant skeletal muscle is an elevation in incomplete fatty acid oxidation rate, often measured as accumulation of acid soluble metabolites $[22,23]$. Consistent with this notion, results from the present study show heightened ASM production in both dietinduced and genetic models of obesity. We further note that complete palmitate oxidation in $d b / d b$ mice is higher than $d b /+$ controls in the absence of pyruvate; however, when moderate $(1 \mathrm{mM})$ or high $(10 \mathrm{mM})$ doses of pyruvate are present, $\mathrm{CO}_{2}$ production from palmitate is similar between skeletal muscle from $d b /+$ and $d b / d b$ mice (Figure 7). At first glance, these findings are striking as they suggest that metabolic flexibility at the level of the mitochondria may actually be better in $d b / d b$ mice. However, this apparent improvement seems to come at the expense of an aberrant response of incomplete fatty acid oxidation (ASMs increase in presence of higher pyruvate concentrations), suggesting that greater mitochondrial overload may be occurring in the $d b / d b$ mice.

In the liver, feeding a Western diet did not alter complete (Figure 7(c)) or incomplete (Figure 7(d)) palmitate oxidation. Also, while a main effect for pyruvate concentration was observed in liver, there was no interaction effect, suggesting that the Western diet had little impact on hepatic fatty acid oxidative capacity or substrate selection at the level of the mitochondria. It is, however, worth noting that as pyruvate concentration rises, the liver of the C57BL6/J mice in the WD-fed group responds by decreasing $\mathrm{CO}_{2}$ liberation and increasing ASM production, whereas the effect of pyruvate on hepatic fat oxidation in $d b /+$ and $d b / d b$ mice is much less pronounced. Elevations in ASMs in response to increasing pyruvate levels could indicate a shift of carbons toward other metabolic outcomes (e.g., ketogenesis); however, the hyperinsulinemia induced in the diet-induced (WD fed) obese mice appears sufficient to maintain normoglycemia, which likely prevents any elevations in circulating ketones.

In adipose tissue, we detected increases in IL- $1 \alpha$ (Figures 5(a) and 5(b)), a key cytokine that signals through the IL-1R1 and likely contributes to inflammatory responses relevant to insulin resistance. In addition, the expression of NOD1 was suppressed in both C57BL/6J mice fed the WD and $d b / d b$ mice (Figures 5(c) and 5(d)). NOD1 activation blocks adipocyte differentiation in vitro [26], suggesting that this pattern recognition receptor may influence the degree of adiposity. We now provide in vivo evidence that NOD1 expression is decreased in two different mouse models of obesity, suggesting that reduced NOD1 expression is a component of adipose tissue expansion. By contrast, CCL2, a chemokine that attracts monocytes and macrophages, was elevated in adipose tissue of both WD-fed mice and $d b / d b$ mice (Figures 5(e) and 5(f)). The CCL2 data are congruent with an increase in the macrophage marker CD68 (Figures 5(g) and 5(h)) and with macrophage accumulation within adipose tissue of obese rodents and humans [47-49].

We note that $d b / d b$ mice display elevations in both glucagon and corticosterone (Figures 4 and 8), which may explain their elevated blood glucose levels relative to mice made obese by WD feeding (Figure 1 ). It is possible that $d b / d b$ mice have reduced ability to properly regulate their hypothalamicpituitary-adrenal axis due to deficiencies in leptin signaling, thus producing elevations in glucose and corticosterone. This interpretation is supported by studies from the Friedman group where specific deletion of the leptin receptor in hypothalamic brain regions results in elevated plasma levels of leptin, glucose, insulin, and corticosterone [50]. Thus, physiological leptin signaling appears to be required for proper corticosterone regulation, which is supported by additional studies [51]. In addition, we observed much less mRNA encoding for the 11- $\beta$-hydroxysteroid dehydrogenase 2 enzyme (Figure 6(h)). Since this enzyme is responsible for converting active steroid to inactive steroid, this observation could help to explain the elevations in circulating corticosterone or prolonged actions of the hormone in $d b / d b$ mice. Finally, elevations in corticosterone and glucagon present in the $d b / d b$ mice, but not the mice fed a WD, are consistent with the higher blood glucose observed in $d b / d b$ mice.

In summary, we conducted a systematic analysis of two fundamental mouse models of obesity, one representing early stages of insulin resistance (WD fed) and the other displaying key features of overt T2D $(d b / d b)$. With various pharmacologic, dietary, and exercise-based interventions being pursued to prevent or reverse the obese and insulin resistance state, our novel results are intended to provide a convenient resource for choosing a mouse model that best mimics the desired stage of human disease to be studied.

\section{Conflicts of Interest}

The authors declare that they have no conflicts of interest.

\section{Acknowledgments}

The authors would like to thank Thomas Martin for technical assistance. The authors also thank the staff of the PBRC Comparative Biology and Cell Biology and Bioimaging Cores for their technical assistance and support. This work was supported by NIH Grants P20-GM103528 (J. Jason Collier) and R01-DK103860 (Robert C. Noland) and a grant from the Physician Medical Education Research Foundation, Knoxville (Matthew S. Boulos, Michael D. Karlstad, and J. Jason Collier). This study used the PBRC 
Cell Biology and Bioimaging Core Facilities that are supported in part by COBRE (P30-GM118430-01) and NORC (NIH P30-DK072476) center grants from the National Institutes of Health.

\section{References}

[1] D. M. Muoio and C. B. Newgard, "Mechanisms of disease: molecular and metabolic mechanisms of insulin resistance and beta-cell failure in type 2 diabetes," Nature Reviews Molecular Cell Biology, vol. 9, no. 3, pp. 193-205, 2008.

[2] V. T. Samuel and G. I. Shulman, "Mechanisms for insulin resistance: common threads and missing links," Cell, vol. 148, no. 5, pp. 852-871, 2012.

[3] G. A. Bray, "Overweight is risking fate. Definition, classification, prevalence, and risks," Annals of the New York Academy of Sciences, vol. 499, pp. 14-28, 1987.

[4] G. A. Bray, "Obesity increases risk for diabetes," International Journal of Obesity and Related Metabolic Disorders, vol. 16, Supplement 4, pp. S13-S17, 1992.

[5] M. F. Gregor and G. S. Hotamisligil, "Inflammatory mechanisms in obesity," Annual Review of Immunology, vol. 29, pp. 415-445, 2011.

[6] J. H. Stern, J. M. Rutkowski, and P. E. Scherer, "Adiponectin, leptin, and fatty acids in the maintenance of metabolic homeostasis through adipose tissue crosstalk," Cell Metabolism, vol. 23, no. 5, pp. 770-784, 2016.

[7] R. H. Unger, "Lipotoxic diseases," Annual Review of Medicine, vol. 53, pp. 319-336, 2002.

[8] R. H. Unger and L. Orci, "Diseases of liporegulation: new perspective on obesity and related disorders," The FASEB Journal, vol. 15, no. 2, pp. 312-321, 2001.

[9] S. J. Burke, M. D. Karlstad, and J. J. Collier, "Pancreatic islet responses to metabolic trauma," Shock, vol. 46, no. 3, pp. 230-238, 2016.

[10] Y. Dor, J. Brown, O. I. Martinez, and D. A. Melton, “Adult pancreatic beta-cells are formed by self-duplication rather than stem-cell differentiation," Nature, vol. 429, no. 6987, pp. 41-46, 2004.

[11] R. B. Sharma, A. C. O'Donnell, R. E. Stamateris et al., "Insulin demand regulates beta cell number via the unfolded protein response," The Journal of Clinical Investigation, vol. 125, no. 10, pp. 3831-3846, 2015.

[12] S. E. Kahn, S. Zraika, K. M. Utzschneider, and R. L. Hull, "The beta cell lesion in type 2 diabetes: there has to be a primary functional abnormality," Diabetologia, vol. 52, no. 6, pp. 1003-1012, 2009.

[13] B. B. Kahn, "Type 2 diabetes: when insulin secretion fails to compensate for insulin resistance," Cell, vol. 92, no. 5, pp. 593-596, 1998.

[14] F. Cinti, R. Bouchi, J. Y. Kim-Muller et al., "Evidence of betacell dedifferentiation in human type 2 diabetes," The Journal of Clinical Endocrinology and Metabolism, vol. 101, no. 3, pp. 1044-1054, 2016.

[15] J. C. Schisler, P. B. Jensen, D. G. Taylor et al., "The Nkx6.1 homeodomain transcription factor suppresses glucagon expression and regulates glucose-stimulated insulin secretion in islet beta cells," Proceedings of the National Academy of Sciences of the United States of America, vol. 102, no. 20, pp. 7297-7302, 2005.
[16] B. L. Taylor, F. F. Liu, and M. Sander, "Nkx6.1 is essential for maintaining the functional state of pancreatic beta cells," Cell Reports, vol. 4, no. 6, pp. 1262-1275, 2013.

[17] R. H. Unger and L. Orci, "The essential role of glucagon in the pathogenesis of diabetes mellitus," Lancet, vol. 1, no. 7897, pp. 14-16, 1975.

[18] S. J. Burke, M. D. Karlstad, K. M. Regal et al., "CCL20 is elevated during obesity and differentially regulated by NF-kappaB subunits in pancreatic beta-cells," Biochimica et Biophysica Acta, vol. 1849, no. 6, pp. 637-652, 2015.

[19] S. J. Burke, H. M. Batdorf, A. E. Eder et al., "Oral corticosterone administration reduces insulitis but promotes insulin resistance and hyperglycemia in male nonobese diabetic mice," The American Journal of Pathology, vol. 187, no. 3, pp. 614626, 2017.

[20] S. J. Burke, M. D. Karlstad, A. E. Eder et al., "Pancreatic betacell production of CXCR3 ligands precedes diabetes onset," BioFactors, vol. 42, no. 6, pp. 703-715, 2016.

[21] R. Klinck, P. Serup, O. D. Madsen, and M. C. Jorgensen, "Specificity of four monoclonal anti-NKx6-1 antibodies," The Journal of Histochemistry and Cytochemistry, vol. 56, no. 4, pp. 415-424, 2008.

[22] R. C. Noland, T. R. Koves, S. E. Seiler et al., "Carnitine insufficiency caused by aging and overnutrition compromises mitochondrial performance and metabolic control," The Journal of Biological Chemistry, vol. 284, no. 34, pp. 22840-22852, 2009.

[23] T. R. Koves, J. R. Ussher, R. C. Noland et al., "Mitochondrial overload and incomplete fatty acid oxidation contribute to skeletal muscle insulin resistance," Cell Metabolism, vol. 7, no. 1, pp. 45-56, 2008.

[24] S. J. Burke, J. J. Collier, and D. K. Scott, "cAMP prevents glucose-mediated modifications of histone H3 and recruitment of the RNA polymerase II holoenzyme to the L-PK gene promoter," Journal of Molecular Biology, vol. 392, no. 3, pp. $578-588,2009$.

[25] D. K. Scott, J. J. Collier, T. T. Doan et al., "A modest glucokinase overexpression in the liver promotes fed expression levels of glycolytic and lipogenic enzyme genes in the fasted state without altering SREBP-1c expression," Molecular and Cellular Biochemistry, vol. 254, no. 1-2, pp. 327-337, 2003.

[26] J. Purohit, P. Hu, S. J. Burke, J. J. Collier, J. Chen, and L. Zhao, "The effects of NOD activation on adipocyte differentiation," Obesity (Silver Spring), vol. 21, no. 4, pp. 737-747, 2013.

[27] M. D. Michael, R. N. Kulkarni, C. Postic et al., "Loss of insulin signaling in hepatocytes leads to severe insulin resistance and progressive hepatic dysfunction," Molecular Cell, vol. 6, no. 1, pp. 87-97, 2000.

[28] J. E. Galgani, C. Moro, and E. Ravussin, "Metabolic flexibility and insulin resistance," American Journal of Physiology, Endocrinology and Metabolism, vol. 295, no. 5, pp. E1009-E1017, 2008.

[29] J. P. Despres, B. Lamarche, P. Mauriege et al., "Hyperinsulinemia as an independent risk factor for ischemic heart disease," The New England Journal of Medicine, vol. 334, no. 15, pp. 952-957, 1996.

[30] B. Jeanrenaud, "Hyperinsulinemia in obesity syndromes: its metabolic consequences and possible etiology," Metabolism, vol. 27, no. 12, Supplement 2, pp. 1881-1892, 1978.

[31] S. M. Haffner, "Hyperinsulinemia as a possible etiology for the high prevalence of non insulin dependent diabetes in Mexican 
Americans," Diabète \& Métabolisme, vol. 13, no. 3, Part 2, pp. 337-344, 1987.

[32] C. Crofts, G. Schofield, C. Zinn, M. Wheldon, and J. Kraft, "Identifying hyperinsulinaemia in the absence of impaired glucose tolerance: an examination of the Kraft database," Diabetes Research and Clinical Practice, vol. 118, pp. 50-57, 2016.

[33] P. Xun, Y. Wu, Q. He, and K. He, "Fasting insulin concentrations and incidence of hypertension, stroke, and coronary heart disease: a meta-analysis of prospective cohort studies," The American Journal of Clinical Nutrition, vol. 98, no. 6, pp. 1543-1554, 2013.

[34] K. C. Sung, M. H. Seo, E. J. Rhee, and A. M. Wilson, "Elevated fasting insulin predicts the future incidence of metabolic syndrome: a 5-year follow-up study," Cardiovascular Diabetology, vol. 10, p. 108, 2011.

[35] O. E. Odeleye, M. de Courten, D. J. Pettitt, and E. Ravussin, "Fasting hyperinsulinemia is a predictor of increased body weight gain and obesity in Pima Indian children," Diabetes, vol. 46, no. 8, pp. 1341-1345, 1997.

[36] A. E. Mehran, N. M. Templeman, G. S. Brigidi et al., "Hyperinsulinemia drives diet-induced obesity independently of brain insulin production," Cell Metabolism, vol. 16, no. 6, pp. 723737, 2012.

[37] R. H. Unger, "Reinventing type 2 diabetes: pathogenesis, treatment, and prevention," The Journal of the American Medical Association, vol. 299, no. 10, pp. 1185-1187, 2008.

[38] R. Alemzadeh, M. D. Karlstad, K. Tushaus, and M. Buchholz, "Diazoxide enhances basal metabolic rate and fat oxidation in obese Zucker rats," Metabolism, vol. 57, no. 11, pp. 15971607, 2008.

[39] A. J. Stunkard, T. T. Foch, and Z. Hrubec, "A twin study of human obesity," The Journal of the American Medical Association, vol. 256, no. 1, pp. 51-54, 1986.

[40] J. C. Florez, "Newly identified loci highlight beta cell dysfunction as a key cause of type 2 diabetes: where are the insulin resistance genes?," Diabetologia, vol. 51, no. 7, pp. 11001110, 2008.

[41] T. M. Frayling, J. C. Evans, M. P. Bulman et al., "Beta-cell genes and diabetes: molecular and clinical characterization of mutations in transcription factors," Diabetes, vol. 50, Supplement 1 , pp. S94-S100, 2001.

[42] S. J. Burke, K. Stadler, D. Lu et al., "IL-1beta reciprocally regulates chemokine and insulin secretion in pancreatic beta-cells via NF-kappaB," American Journal of Physiology, Endocrinology and Metabolism, vol. 309, no. 8, pp. E715-E726, 2015.

[43] R. H. Unger and A. D. Cherrington, "Glucagonocentric restructuring of diabetes: a pathophysiologic and therapeutic makeover," The Journal of Clinical Investigation, vol. 122, no. 1, pp. 4-12, 2012.

[44] P. Raskin and R. H. Unger, "Hyperglucagonemia and its suppression. Importance in the metabolic control of diabetes," The New England Journal of Medicine, vol. 299, no. 9, pp. 433436, 1978.

[45] Y. Lee, E. D. Berglund, X. Yu et al., "Hyperglycemia in rodent models of type 2 diabetes requires insulin-resistant alpha cells," Proceedings of the National Academy of Sciences of the United States of America, vol. 111, no. 36, pp. 13217-13222, 2014.

[46] J. Y. Kim-Muller, J. Fan, Y. J. Kim et al., "Aldehyde dehydrogenase 1a3 defines a subset of failing pancreatic beta cells in diabetic mice," Nature Communications, vol. 7, article 12631, 2016.
[47] S. P. Weisberg, D. Hunter, R. Huber et al., "CCR2 modulates inflammatory and metabolic effects of high-fat feeding," The Journal of Clinical Investigation, vol. 116, no. 1, pp. 115-124, 2006.

[48] C. N. Lumeng, J. L. Bodzin, and A. R. Saltiel, "Obesity induces a phenotypic switch in adipose tissue macrophage polarization," The Journal of Clinical Investigation, vol. 117, no. 1, pp. 175-184, 2007.

[49] S. P. Weisberg, D. McCann, M. Desai, M. Rosenbaum, R. L. Leibel, and A. W. Ferrante Jr., "Obesity is associated with macrophage accumulation in adipose tissue," The Journal of Clinical Investigation, vol. 112, no. 12, pp. 1796-1808, 2003.

[50] P. Cohen, C. Zhao, X. Cai et al., "Selective deletion of leptin receptor in neurons leads to obesity," The Journal of Clinical Investigation, vol. 108, no. 8, pp. 1113-1121, 2001.

[51] F. P. Pralong, R. Roduit, G. Waeber et al., "Leptin inhibits directly glucocorticoid secretion by normal human and rat adrenal gland," Endocrinology, vol. 139, no. 10, pp. 42644268, 1998. 


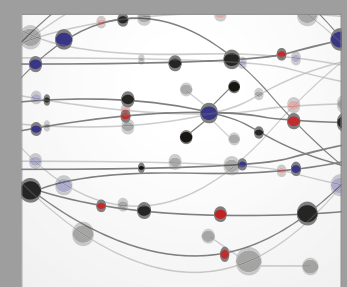

The Scientific World Journal
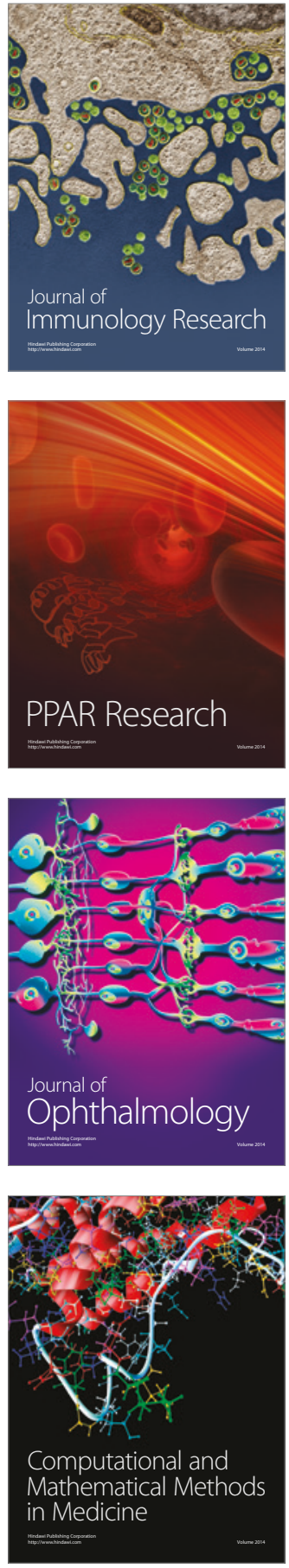

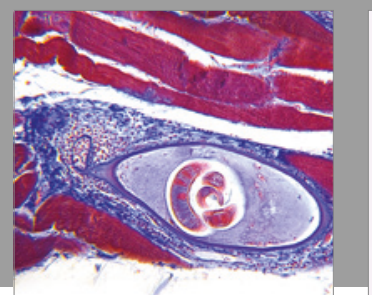

Gastroenterology Research and Practice
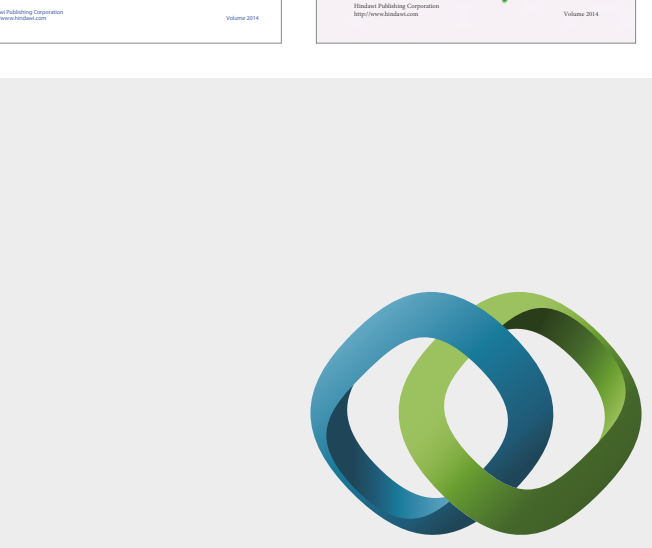

\section{Hindawi}

Submit your manuscripts at

https://www.hindawi.com
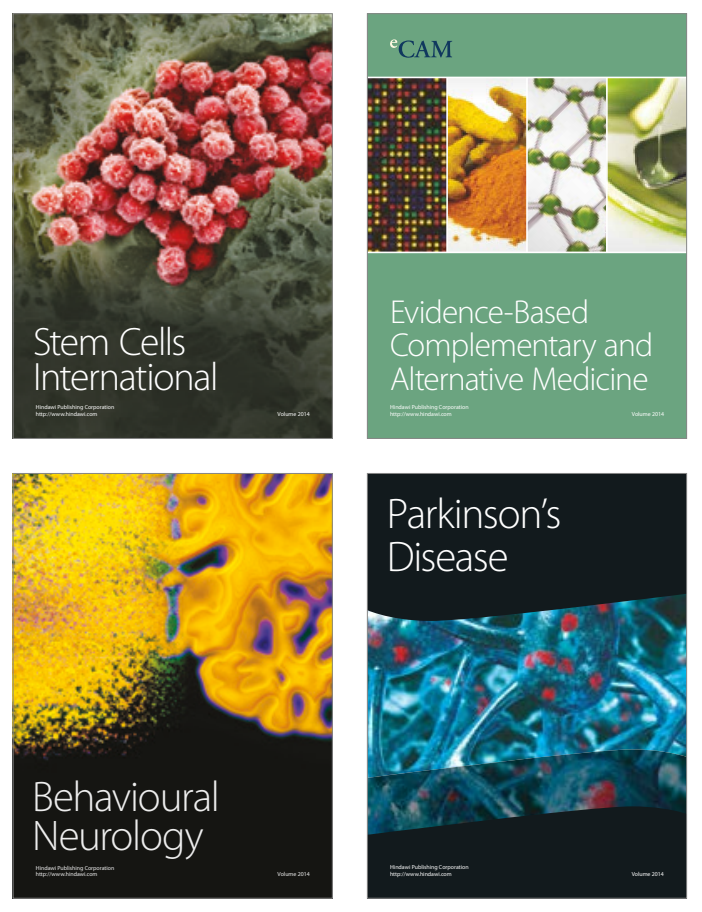
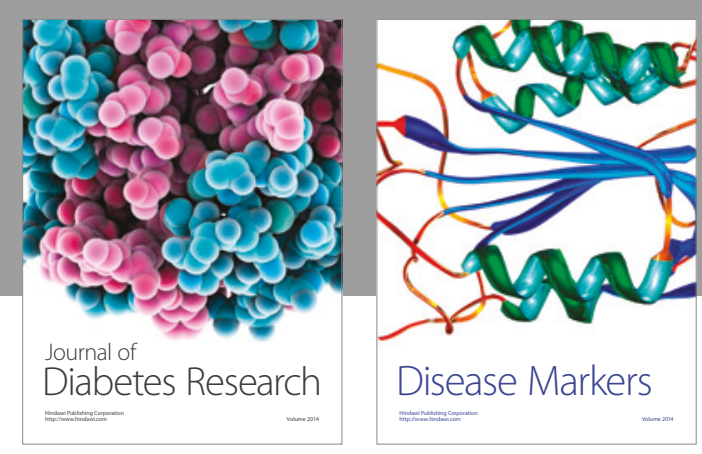

Disease Markers
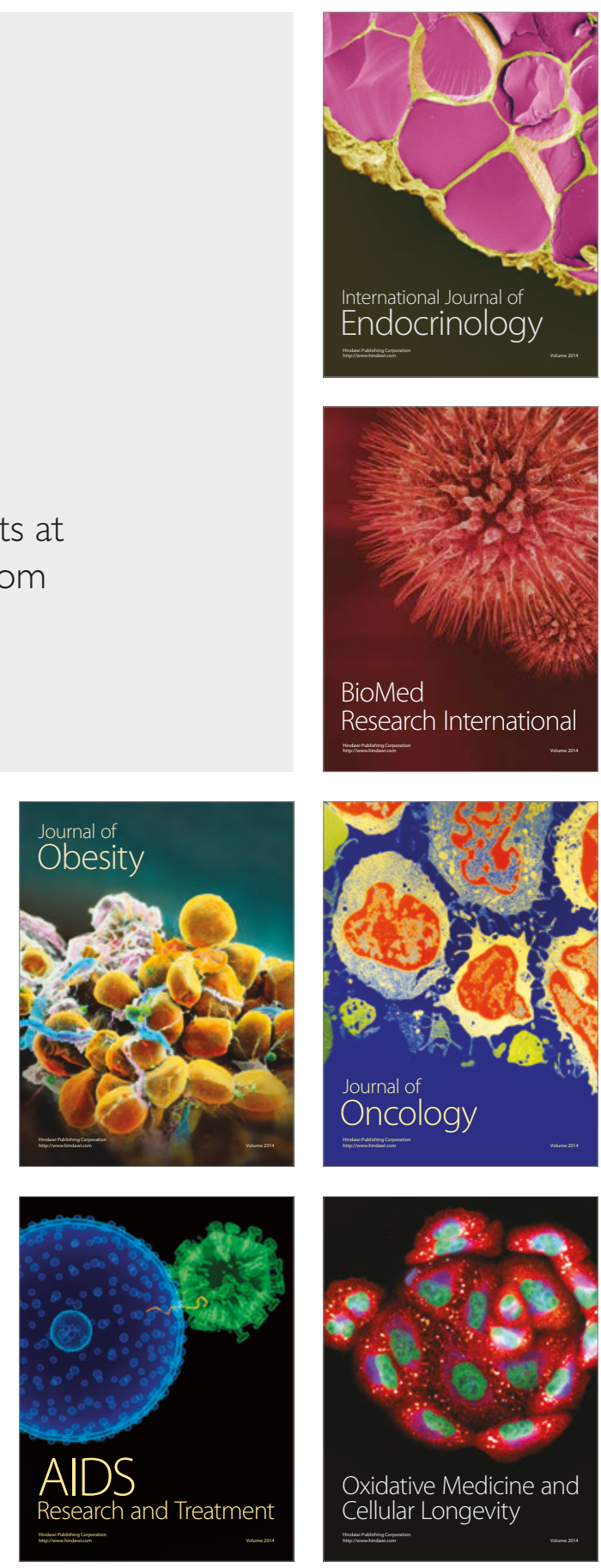